\title{
On the Role of Arachidonic Acid in M-Current Modulation by Muscarine in Bullfrog Sympathetic Neurons
}

\author{
Alvaro Villarroel \\ Howard Hughes. Medical Institute, Department of Neurobiology and Behavior, SUNY at Stony Brook, Stony Brook, New \\ York $11794-5230$
}

The modulation by muscarine or LHRH of the potassium M-current $\left(I_{M}\right)$ in whole-cell voltage-clamped bullfrog sympathetic neurons presents an initial phase of current reduction, followed, after agonist removal, by a transient enhancement or "overrecovery." Employing a fast solution exchange system, an inhibitory process and an enhancing process were distinguished kinetically. The extent of overrecovery increased with the extent of the preceding inhibition. The rate and degree of inhibition increased with the concentration of agonist. In contrast, the rate of recovery and the extent of overrecovery were independent. The half-lives of the inhibitory and enhancing processes were 21 and $53 \mathrm{sec}$, respectively.

Several observations suggest that arachidonic acid (AA) may be involved in overrecovery: (1) AA enhanced $I_{m}$ in a dose-dependent and reversible manner, with an $\mathrm{IC}_{50}$ of $\mathbf{2 . 8}$ $\mu M$. (2) Muscarine inhibited the A-current $\left(I_{A}\right)$, a potassium current that is blocked by AA. (3) Phospholipase $A_{2}$ inhibitors (quinacrine and bromophenacyl bromide) and a lipoxygenase inhibitor (nordihydroguaiaretic acid) prevented overrecovery, without affecting the rate or extent of $I_{M}$ inhibition significantly. However, kinetic analysis indicates that these drugs were preventing overrecovery by prolonging the halflife of the inhibitory process to $>80 \mathrm{sec}$ (e.g., not necessarily by blocking the enhancing pathway). In addition, the extent of $I_{A}$ inhibition was less than expected if AA was mediating both $I_{M}$ enhancement and $I_{A}$ inhibition.

The observed relation between extent and rate of overrecovery, and the action of arachidonic acid metabolism inhibitors can be accounted for by a model proposing that the agonist alters the equilibrium between three pools of M-channels.

IKey words: M-current, A-current, potassium current, modulation, inhibition, overrecovery, kinetics, bromophenacyl bromide, quinacrine, nordihydroguaiaretic acid, fast flow, arachidonic acid, muscarine, luteinizing hormone-releasing hormone, bullfrog sympathetic neurons]

\footnotetext{
Received Nov. 18, 1993; revised Apr. 7, 1994; accepted May 12, 1994.

I am indebted to Dr. Paul R. Adams for providing the facilities of his laboratory for this work, and for his support and comments. I thank Dr. Thomas Schwarz and Dr. Hector Lopez for comments on earlier versions of the manuscript. I thank Rob Burgess for proofreading the manuscript. I thank Barry Burbach for tissue culture and expert technical assistance, and Lole Juarbe for digging in search of the words "tacit," "fluent," and "muted."

Correspondence should be addressed to Alvaro Villarroel, Department of Molecular and Cellular Physiology, Beckman Center, Stanford University Medica Center, Stanford, CA 94305-5426.

Copyright $(C) 1994$ Society for Neuroscience $0270-6474 / 94 / 147053-14 \$ 05.00 / 0$
}

Modulation of ionic channels by neurotransmitters plays a central role in the integration of synaptic input in the nervous system (Kaczmarek and Levitan, 1987; Nicoll, 1988) and can have dramatic effects on the firing pattern of excitable cells (Hille, 1992). In bullfrog sympathetic neurons, activation of muscarinic reccptors by acetylcholine released presynaptically causes the slow excitatory postsynaptic potential, due to suppression of the M-current $\left(I_{\mathrm{M}}\right)$ (Adams and Brown, 1982), a noninactivating voltage-dependent potassium current (Brown and Adams, 1980; Adams et al., 1982a,b). Blockade of $I_{\mathrm{M}}$ leads to depolarization of the membrane potential, an increase in cell input resistance, and an increase in neuronal excitability (reviewed in Adams et al., 1986). In addition to muscarine, other neurotransmitters and neuropeptides suppress $I_{\mathrm{M}}$ (reviewed in Brown, 1988; Bosma et al., 1991). Other conductances, such as calcium currents, are also modulated by the same neuropeptides (Bley and Tsien, 1990; Jones, 1992).

The dynamics of M-current modulation are what ultimately determine the role of this current in the integration of the presynaptic input and the generation of the slow excitatory postsynaptic potential. Furthermore, the knowledge of the modulation kinetics is essential to understand the role of second messenger systems in the modulatory process. However, while considerable effort has been devoted to trying to identify the components involved in $\mathrm{M}$-current modulation (reviewed in Brown, 1988; Bosma et al., 1991), little is known about the dynamics of the system.

The time course of M-current modulation is complex, with an initial phase of current reduction followed by a phase of enhancement (once the agonist is removed) termed "overrecovery" (Pfaffinger, 1988). This biphasic response is not unique to the M-current or bullfrog neurons. It has been observed in calcium currents (Boland and Bean, 1993) and in other preparations (Forscher et al., 1986; Kasai, 1991; Yakel, 1991). Previous analysis has shown that the rate of recovery of $I_{M}$ from inhibition is slow (Jones, 1992; Lopez, 1992), that the rate of inhibition increases with agonist concentration in cells dialyzed with GTP $\gamma$ S (Lopez, 1992), and that the rate of inhibition is reduced in cells dialyzed with GDP $\beta$ S (Simmons et al., 1992). Interestingly, the reduction in the rate of inhibition of $I_{\mathrm{M}}$ by internal GDP $\beta$ S is specific to the agonist (muscarine, LHRH, or substance P) used to evoke the response (Simmons and Mather, 1991).

$I_{\mathrm{M}}$ can be enhanced without inhibition in response to $\beta$ adrenergic agonists in smooth muscle (Sims et al., 1988), and in response to somatostatin in brainstem (Jacquin et al., 1988) and hippocampal neurons (Moore et al., 1988). This suggests that in bullfrog neurons muscarine may be triggering two parallel 
pathways, one that increases $I_{\mathrm{M}}$ and another that inhibits the current. Recently, it has been found that arachidonic acid (AA) can augment $I_{M}$ (Schweitzer et al., 1990; Bosma et al., 1991), acting via the lipoxygenase pathway (Schweitzer et al., 1990, 1993; Yu et al., 1991), suggesting that AA may participate in overrecovery. However, these studies may not reflect the true extent of the effects of AA on $I_{\mathrm{M}}$ due to its adsorption to the recording chamber and other surfaces (Samples et al., 1989; Schweitzer et al., 1993).

Here, the hypothesis that the enhancement phase is mediated by agonist-mediated AA release is tested. Evidence for the production of $\mathrm{AA}$ has been sought monitoring the A-current, a potassium current blocked by AA (Villarroel, 1993). The effect of AA on $I_{\mathrm{M}}$ has been reevaluated employing a perfusion system that minimizes the adsorption problem. It is shown that $I_{\mathrm{M}}$ is more sensitive to AA than previously reported, and that blockers of AA metabolism can prevent overrecovery. Furthermore, $I_{\mathrm{A}}$, which is more sensitive to AA than $I_{\mathrm{M}}$, is inhibited by muscarine. However, the extent of muscarine-mediated $I_{\mathrm{A}}$ inhibition and the slow time course of $I_{\mathrm{M}}$ recovery from inhibition after treatment with AA metabolism inhibitors conflict with the hypothesis that stimulation of AA release by muscarine underlies the overrecovery phase.

\section{Materials and Methods}

Cell preparation, solutions, and electrophysiolngy. Bullfrog (Rana catesbeiana) sympathetic neurons were isolated from lumbar VIIIth, IXth, and Xth ganglia by enzymatic treatment and trituration (Kuffler and Sejnowski, 1983). Isolated neurons were stored at $8^{\circ} \mathrm{C}$ in $80 \% \mathrm{~L}-15$ medium (GIBCO, Ithaca, NY), supplemented with $6-10 \%$ fetal calf serum, $0.2 \%$ glucose, and $1 \mathrm{~mm} \mathrm{CaCl}$, and used after $1-7 \mathrm{~d}$ in culture. Currents were recorded at room temperalure $\left(22-24^{\circ} \mathrm{C}\right)$ in continuous whole-cell voltage-clamp mode (Hamill et al., 1981) using a List EPC7 amplifier. Seventy to eighty percent series resistance was compensated. Fire-polished, filamented hard glass electrodes with a tip diameter of $\sim 3.3 \mu \mathrm{m}$ were used. The total access resistance varied from 2 to $10 \mathrm{M} \Omega$. The intracellular solution was $90 \mathrm{~mm} \mathrm{~K}$ aspartate, $20 \mathrm{~mm} \mathrm{KCl}, 1.5 \mathrm{~mm}$ $\mathrm{MgCl}_{2}, 1.5 \mathrm{~mm} \mathrm{Na}$ ATP, $5 \mathrm{~mm}$ HEPES, $0.2 \mathrm{~mm}$ EGTA, $60 \mu \mathrm{M} \mathrm{CaCl}$ ( $80 \mathrm{~nm}$ estimated free calcium), and $0.2 \mathrm{~mm} \mathrm{Na} \mathrm{Na}_{3}$. The $\mathrm{pH}$ was adjusted to 7.2 . The extracellular solution was $115 \mathrm{~mm} \mathrm{NaCl}, 2.5 \mathrm{~mm}$ $\mathrm{KCl}, 1 \mathrm{~mm} \mathrm{MgCl}, 2 \mathrm{~mm} \mathrm{CaCl}, 5 \mathrm{~mm}$ HEPES, and $10 \mathrm{~mm}$ glucose (pH 7.2). In experiments with arachidonic acid, manganese Ringer was used, which was made by substituting manganese for calcium and adding 1 mM TEA, $0.2 \mathrm{~mm} d$-tubocurarine, and $200 \mathrm{~nm}$ TTX. These solutions caused a $16 \mathrm{mV}$ junction potential that was subtracted in the voltages reported.

Muscarine was from Research Biochemicals Inc. (Natick, MA), LHRH from Peninsula (Belmont, CA), and HEPES and arachidonic acid were from Calbiochem (San Diego, CA). The rest of the chemicals were from Sigma (St. Louis, MO). Arachidonic acid, bromophenacyl bromide, and nordihydroguaiaretic acid were prepared from a stock solution in dimethyl sulfoxide (DMSO), to a final DMSO concentration of less than $0.25 \%$. At this concentration, DMSO did not have an appreciable effect on the M- or A-currents. DMSO was dehydrated with "molecular sieves" (8-12 mesh size, $3 \AA$ nominal diameter) (Fisher, Fair Lawn, NJ).

The access resistance and capacitance were estimated by compensating for the capacitative transients elicited by $10 \mathrm{mV}$ hyperpolarizing pulses. The average capacitance was $78.3 \pm 14.5 \mathrm{pF}$. Currents were digitized and acquired on line via a Data Translation DT2801A interface (4096 current levels) and stored in a Compaq 286 computer (IBM compatible), using software written in ASYST language (ASYST 1.53, Macmillan Software Company, NY). Continuous acquisition was done at low frequency $(10 \mathrm{~Hz})$. When voltage pulses were delivered, the software increased the acquisition frequency and stored the data under a different file name. Therefore, the current during the voltage pulses was not present in the low-frequency acquisition file. The program automatically filled this gap with interpolated values for the current. Currents were filtered with an 8-pole Bessel filter (Frequency devices, model 902) at one-half the fast acquisition frequency (typically between 200 and 500
$\mathrm{Hz}$ ). The output of the EPC7 was amplified to expand $\pm 10 \mathrm{~V}$ with amplifiers from a chart recorder (Astro Med ASC 909).

Fast flow system apparatus. The fast flow system used was a variation of the U-tube described by Krishtal and Pidoplichko (1980). It consisted in a delivery pipette made of soft glass, with a tip diameter of $\sim 100$ $\mu \mathrm{m}$ after fire polishing, positioned $\sim 150 \mu \mathrm{m}$ from the cell, in which the test solution was continuously circulating, and drained before exiting to the bath through an internal capillary positioned $\sim 50 \mu \mathrm{m}$ from the tip of the delivery pipette. The internal capillary was connected to an electronic pinch valve (NResearch, Maplewood, NJ). Opening and closing of the valve was controlled with a pulse generator (World Precision Instruments 1830,1831$)$. A suction pipette $(\sim 150 \mu \mathrm{m}$ tip diameter) was positioned $\sim 150 \mu \mathrm{m}$ from the cell body opposite to the delivery pipette. This pipette had several functions: to keep the variations in flow caused by the application of solution to a minimum; to prevent the test solution from reaching other cells, to minimize dilution of the test solution before reaching the cell, and to increase the speed of removal of test solution after ending the application. The improvement of the performance of the flow system provided by the suction pipette was dramatic. The suction of the internal capillary and the suction pipette were controlled by changing the height of the waste tubing. The flow at the delivery pipette was controlled by changing the height of the reservoirs containing test solutions. To avoid changes in flow during the experiment, isobaric reservoirs were used. The isobaric reservoir consisted of a $60 \mathrm{ml}$ plastic syringe, hermetically closed with a rubber stopper. A $5 \mathrm{ml}$ plastic pipette was introduced through a hole in the rubber stopper. In this apparatus the position of the pipette determines the hydraulic pressure in the reservoir. Therefore, as long as the fluid level is above the pipette, the flow is constant.

The performance of the flow system was assessed by applying high concentrations of potassium. At depolarized holding potentials, the current flows mainly through noninactivating potassium M-channels. Figure $1 A a$ shows current relaxations evoked by $1 \mathrm{sec}$ pulses to -70 and $-100 \mathrm{mV}$ as the $\mathrm{M}$-channels closed at rates governed by the command voltage. On repolarization to the $-40 \mathrm{mV}$ holding potential there were outward current relaxations as M-channels reopened, which were superimposed on the transient outward current, $I_{\mathrm{A}}$, which increased as the hyperpolarizing voltage pulse removed more inactivation. Figure $1 \mathrm{Ab}$ shows the currents evoked with the same voltage protocol during fast application of $9.53 \mathrm{~mm}$ potassium. The reversal potential shifted $31 \mathrm{mV}$, from $-96 \mathrm{mV}$ in $2.5 \mathrm{~mm}$ potassium, to $-65 \mathrm{mV}$ in high potassium, close to a $33 \mathrm{mV}$ shift expected for a pure potassium current (Fig. $1 B$ ). The size of $I_{\mathrm{M}}$ and $I_{\mathrm{A}}$ decreased as the driving force for potassium was reduced. The time to reach $90 \%$ of the final holding current value from the initiation of the application was $56.0 \pm 14.7$ msec $(n=6)$.

Data analysis. Analysis was done with programs written in ASYST language. All fits were done following the least square criterion, using the Gauss-Newton method, employing double precision real numbers. Other software used was LOTUs 1232.1 (Lotus Development Co., Cambridge, MA) and sigmaplot 4.1 (Jandel Co., Corta Madera, CA). Results are expressed as mean \pm standard deviation $(n=$ number of experiments), or as mean \pm standard error of the mean where indicated.

Relation between rate and extent of inhibition. In a simple triangular three-state scheme for inhibition, in which the channel is in equilibrium between three states, open, closed, and inhibited:

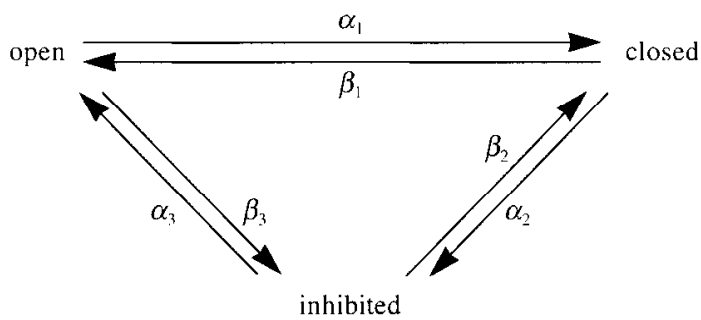

the observed current (I) at steady state is (Szabó, 1969) $I / I_{\max }=\mathrm{K} 1$ / $(\mathrm{K} 1+\mathrm{K} 2+\mathrm{K} 3)$, where $\mathrm{K} 1=\beta_{1} \beta_{2}+\beta_{1} \alpha_{3}+\alpha_{2} \alpha_{3}, \mathrm{~K} 2=\alpha_{1} \beta_{2}+\alpha_{1} \alpha_{3}$ $+\beta_{2} \beta_{3}$, and $\mathrm{K} 3=\alpha_{1} \alpha_{2}+\beta_{1} \beta_{3}+\alpha_{2} \beta_{3}$, where $\alpha_{1}$ and $\beta_{1}$ are the rate transitions within the open and closed state, $\beta_{3}$ and $\alpha_{2}$ are the rate transitions to the inhibited state, and $\alpha_{3}$ and $\beta_{2}$ are the rate transitions from the inhibited state to the open and closed state, respectively.

At the holding potential employed in these experiments $(-39$ to -44 


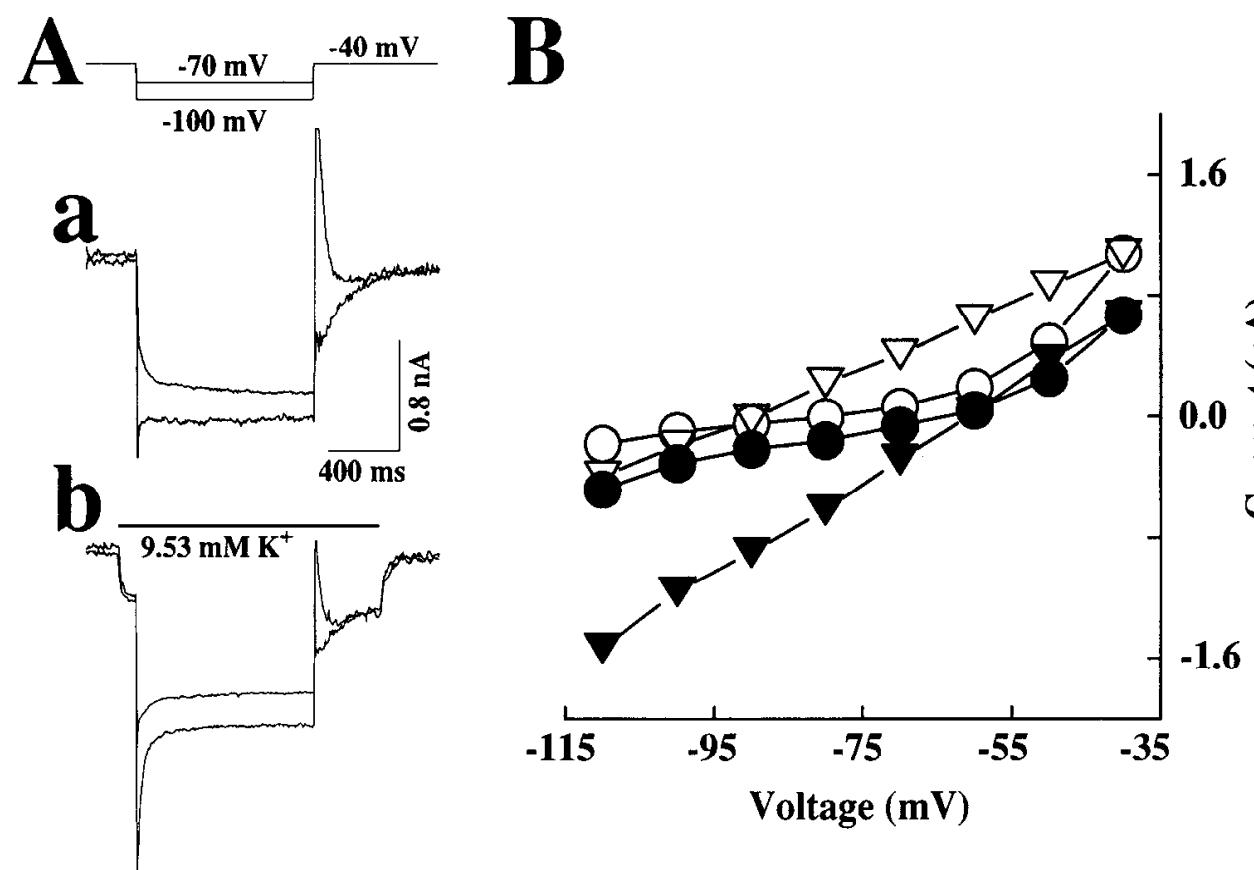

Figure 1. Flow system performance. $A a$, M-current relaxations in response to $1 \mathrm{sec}$ hyperpolarizing voltage pulses to -70 and $-100 \mathrm{mV}$. The voltage was 2. held at $-40 \mathrm{mV}$. The outward direction of the relaxation evoked during the pulse to $-100 \mathrm{mV}$ indicates that the reversal potential was close to that voltage. $A h$. Same protocol as in $A a$, imposed with fast application of high potassium Ringer. The relaxation evoked at -40 $\mathrm{mV}$ became outward as the reversal potential changed. $I_{\mathrm{M}}$ and $I_{\mathrm{A}}$ were reduced as the driving force for potassium decreased. $B$, Current-voltage relation constructed from the data in $A$ in control $(O, \nabla)$ and during fast application of high potassium Ringer $(\boldsymbol{0}, \boldsymbol{\nabla}) . \nabla, \boldsymbol{\nabla}$, instantaneous current at the onset of the voltage pulse; $O, \bullet$, current at the end of the voltage pulse. The reversal potential shifted from -96 to $-65 \mathrm{mV}$ during high potassium application.

$\mathrm{mV}$ ), $\alpha_{1} \approx \beta_{1}$ (Adams et al., 1982a). Assuming $\alpha_{3}=\beta_{2}$, and $\beta_{3}=\alpha_{2}$, then $\mathrm{K} 1=\alpha_{3} \cdot\left(2 \cdot \beta_{1}+\beta_{3}\right), \mathrm{K} 2=\alpha_{3} \cdot\left(2 \cdot \beta_{1}+\beta_{3}\right)$, and $\mathrm{K} 3=\beta_{3} \cdot\left(2 \cdot \beta_{1}+\right.$ $\left.\beta_{3}\right)$; the observed current will be $I=I_{\max } \cdot\left(\alpha_{3} /\left(2 \cdot \alpha_{3}+\beta_{3}\right)\right)$.

Assuming that $\beta_{1} \gg \beta_{3}$, and $\beta_{1} \gg \alpha_{3}$, the forward time constant of inhibition, $\tau_{f}$, will be $\tau_{f}=1 /\left(\beta_{3}+\alpha_{3}\right)$. Assuming that in resting conditions $\beta_{3} \ll \alpha_{3}$, the time constant of recovery, $\tau_{b}$, will be $\tau_{b}=1 / \alpha_{3}$; therefore, $I=I_{\max } \cdot\left(\tau_{f} /\left(\tau_{f}+\tau_{b}\right)\right)$.

\section{Results}

\section{Overrecovery and inhibition are related}

Muscarine and luteinizing hormone-releasing hormone (LHRH) reversibly reduced the holding current in neurons voltage clamped at $-39 \mathrm{mV}$. In bullfrog sympathetic neurons the
M-current $\left(I_{M}\right)$ is the main current present when the cells are clamped at depolarized potentials because it does not inactivate (Adams et al., 1982a). A fast perfusion system was employed to deliver muscarine or LHRH. The solution exchange was completed in less than $150 \mathrm{msec}$. On removal of agonist after prolonged applications, the current transiently reached a value that was bigger than control (Fig. $2 A$ ). This rebound facilitation has been called overrecovery (Pfaffinger, 1988). Enhancement was observed only after inhibition. Figure $2 A$ shows that overrecovery was bigger when it was preceded by larger inhibition (produced by different concentrations of agonist). The extent of overrecovery faded with repeated applications of agonist (see
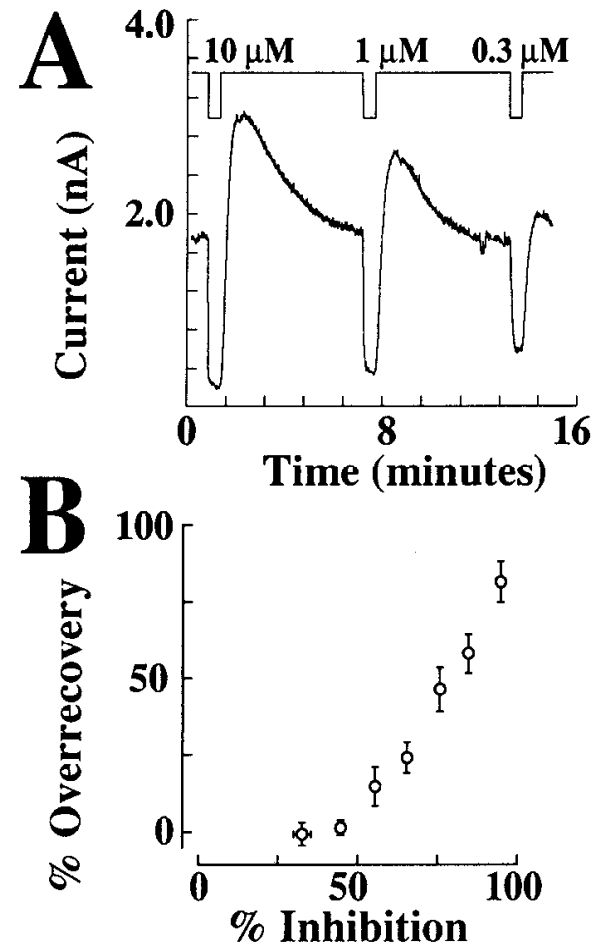

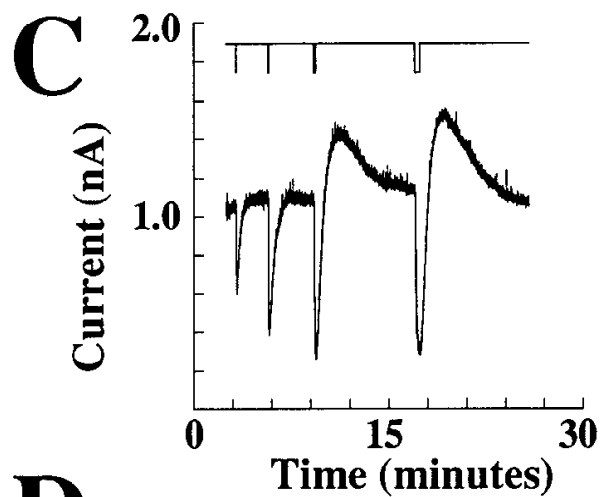

D

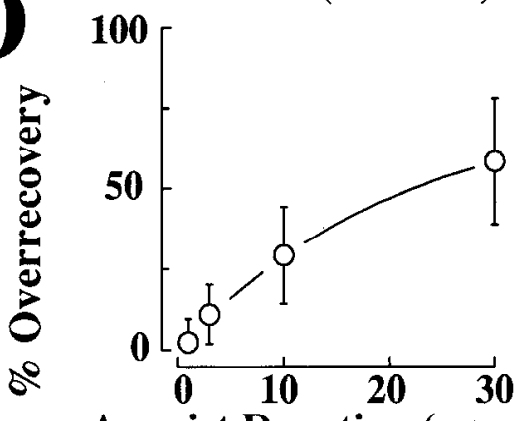

Agonist Duration (seconds)
Figure 2. Relation between extent of inhibition and overrecovery. $A$, There was more overrecovery when it was preceded by stronger inhibitions: typical response to $30 \mathrm{sec}$ fast application of different concentrations of muscarine in a cell voltage clamped at -39 $\mathrm{mV}$. $B$, Plot of the magnitude of overrecovery versus the degree of inhibition observed in response to $30 \mathrm{sec}$ applications of different concentrations of muscarine (from 0.1 to $50 \mu \mathrm{M}$ ). Error bars are the standard errors of the mean. The data were pooled from eight experiments. $C$, Typical response to increasing durations of applications of 10 $\mu \mathrm{M}$ muscarine in a cell voltage clamped at $-40 \mathrm{mV}$. The duration of the fast application was (from left to right) 1,3 , 10 , and 30 sec. $D$, Relation between overrecovery and duration of agonist application. Each point represents the average of (from left to right) 10, 10, 9, and 8 experiments. Error bars are standard deviations. The solid line is the best fit of the function \% overrecovery $=76.6-77.1 \cdot e^{- \text {time/ } \tau}$, with $\tau=19.8$ sec. 


\section{A}

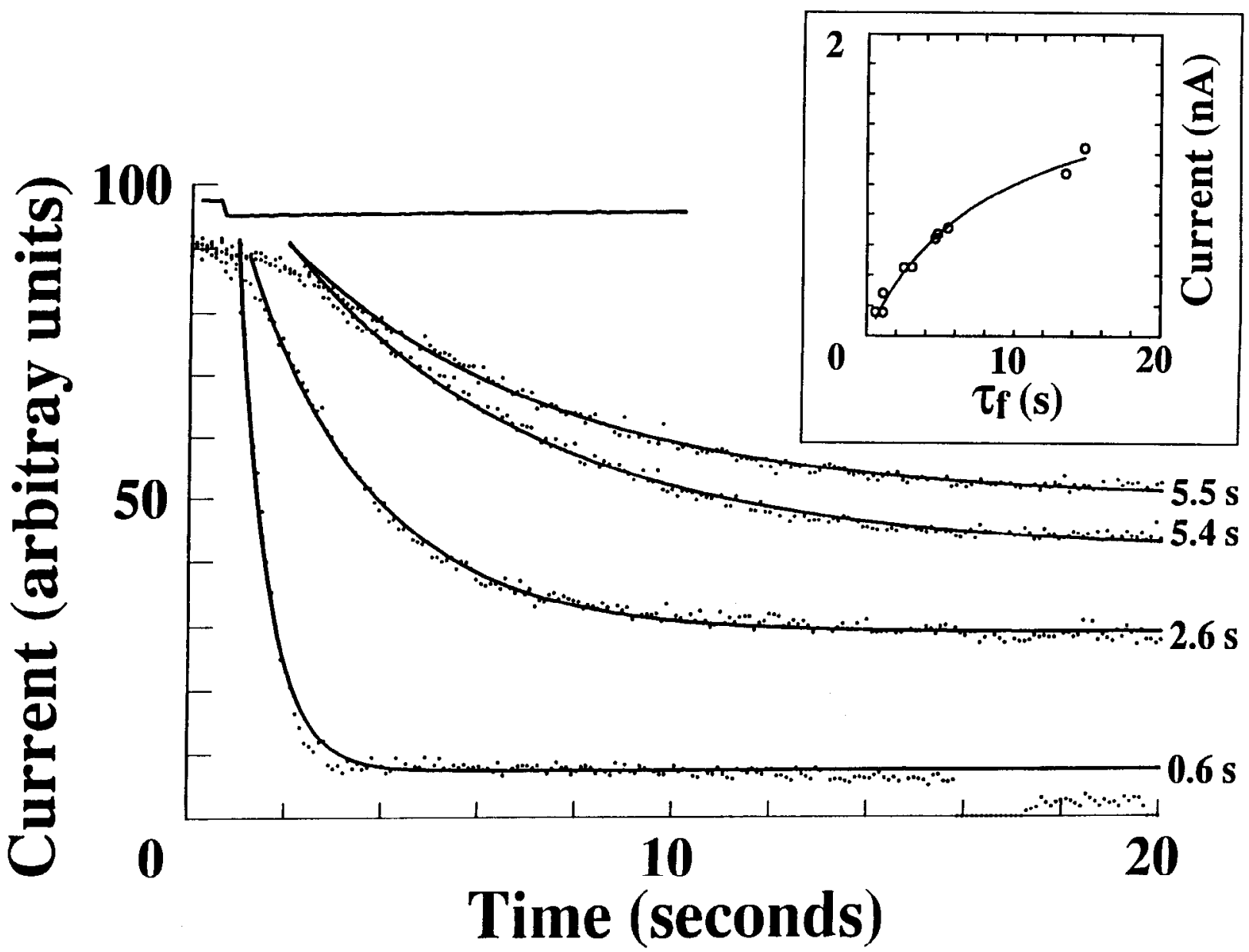

Figure 3. Rate and extent of recovery are related, while rate and extent of overrecovery are not. $A$, Representative traces obtained after repetitive applications of agonist in a neuron voltage clamped at $-39 \mathrm{mV}$ (dotted lines). Continuous lines are the result of the best fit of a monoexponential curve to the data, with the time constants indicated at the right of the curve. The records were obtained in response to a 30 sec application of, from bottom to top, $50,5,1$, and $1 \mu \mathrm{M}$ muscarine. The response to the same concentration of agonist became slower with subsequent applications (see Results). Note that the delay increased as the response became slower. The top (rectangular) trace is the response to a fast application of high potassium Ringer $(9.53 \mathrm{~mm}$ ) (different ordinal scale than the traces in the response to agonist). Inset, Relation between rate and final current. The relation $I=I_{\max } \cdot \tau_{f} /\left(\tau_{f}+\tau_{b}\right)$ was fitted to the data, where $\tau_{f}$ is the time constant of inhibition determined experimentally, and $I_{\max }$ and $\tau_{b}$ are free parameters, corresponding to the maximal current and the time constant of recovery, respectively (see Materials and Methods). From this fit, $\tau_{b}$ was estimated to be $18 \pm 5.5 \mathrm{sec}$. In the same experiment, the time constant of recovery was $20.9 \pm 5.9 \mathrm{sec}$. The data points in the insets were obtained from the rates of inhibition to $30 \mathrm{sec}$ fast application of different concentrations of muscarine, from left to right (in $\mu \mathrm{M}$ ), 50, 50, 50, 5, 5, $1,1,1,0.1,0.1$. B. Recovery from $1 \mathrm{sec}$ (dotted line) and $30 \mathrm{sec}$ (solid line) application of $10 \mu \mathrm{M}$ muscarine. Holding potential was - $39 \mathrm{mV}$. The current traces have been scaled. If M-current modulation behaves as a two-state Markov process, the rate of overrecovery should get faster as the final current is larger. However, the rates of recovery were similar even though the current overrecovered to a value $60 \%$ bigger than control in the latter case (see inset). Similar results were obtained in 10 experiments. Agonist applications are indicated by the bars. $C$, Fifty micromolar muscarine was applied for $30 \mathrm{sec}$. At the peak of the overrecovery, muscarine was applied again. The recovery phase was normalized and supcrimposed. The solid line is the recovery from the second response. The dotted line is the recovery after the first agonist application. The rates were comparable in both cases. Inset, Full record of the response to $30 \mathrm{sec}$ fast application of $50 \mu \mathrm{M}$ muscarine. Holding potential was - $39 \mathrm{mV}$. At the peak of inhibition a $-20 \mathrm{mV}$ voltage step was imposed, producing the inward currents in the figure. Similar results were obtained in six experiments. $D$, Plot of the extent of overrecovery versus the rate constant of recovery. $O$, data from experiments (10 neurons) in which the duration of agonist application was changed, and the concentration of muscarine was 10 or $50 \mu \mathrm{M}$. 9 , data from experiments (eight neurons) in which the concentration of agonist was changed, and the duration of agonist application was $30 \mathrm{sec}$. Error bars are the standard errors of the mean.

Marrion et al., 1991), but the relation between the extent of inhibition and the extent of overrecovery was maintained regardless of the order of application of the different agonist concentrations. Figure $2 B$ shows a plot of inhibition versus overrecovery. Overrecovery also increased as the duration of agonist application increased up to $30 \mathrm{sec}$, the longest duration tested (Fig. $2 C, D$ ). In contrast, the full inhibitory response was reached in less than $10 \mathrm{sec}$ (Fig. $3 \mathrm{~A}$ ), indicating that the transitions underlying overrecovery had a slower overall rate than the tran- sitions underlying inhibition. The time constant of the manifestation of overrecovery was $19.8 \mathrm{sec}$, about 15 times slower than that of inhibition (see below and Table 1).

Rate and extent of inhibition are related, while rate and extent of overrecovery are not

The response to agonist had a sigmoidal time course. After an initial short latency $(\sim 200 \mathrm{msec})$, the predominant phase of inhibition could be approximated by a monoexponential func- 

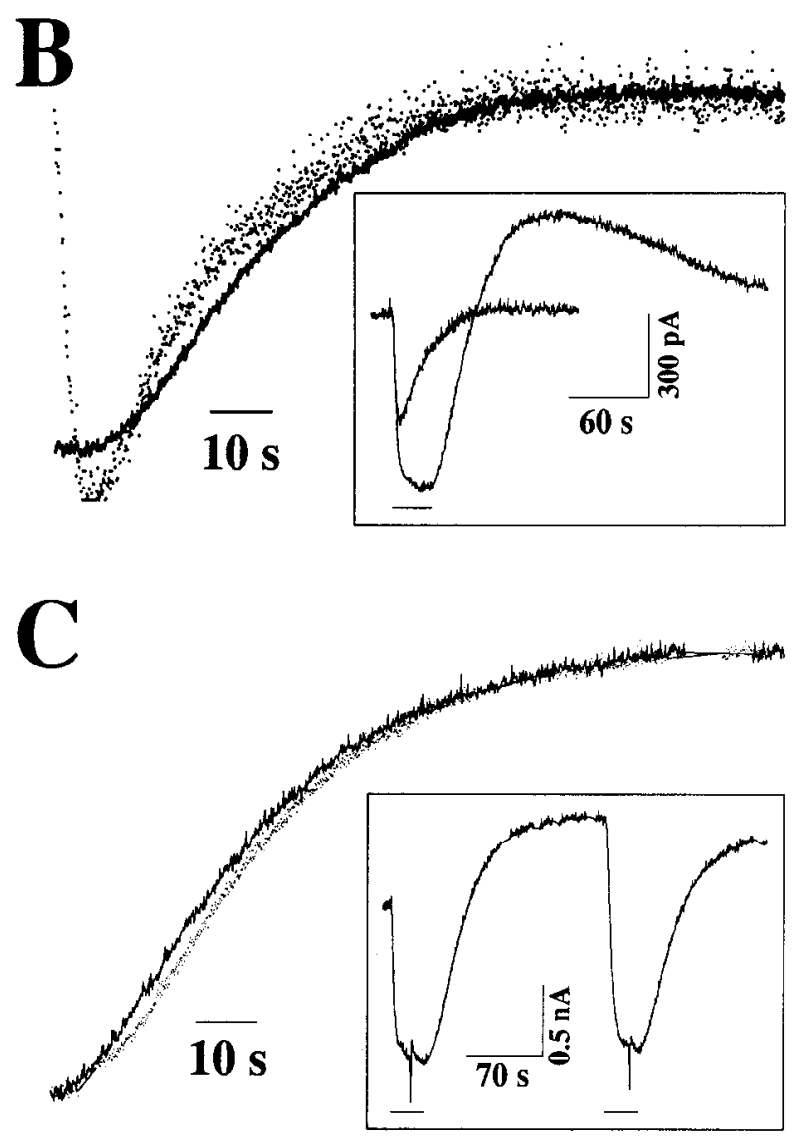

\section{D}

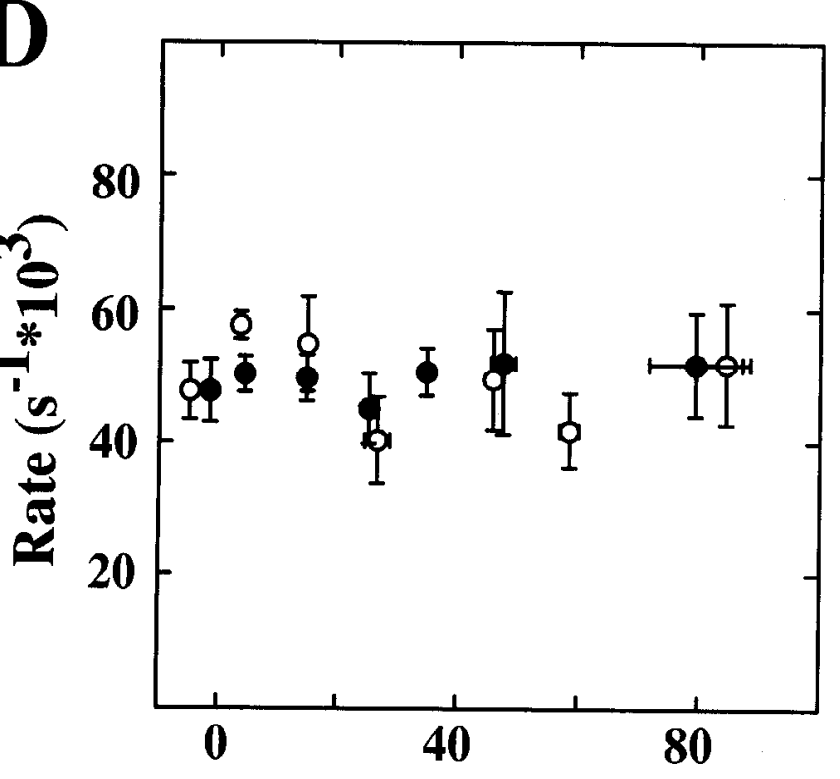

Current Increase

Figure 3. Continued.

tion. In many cells, a secondary slow phase of holding current reduction that represented less than $10 \%$ of the response was observed. To estimate the rate constant of inhibition, a monoexponential function was fitted to the data from $200 \mathrm{msec}$ after the onset of the response to $10 \mathrm{sec}$ or less. The rate constant of inhibition in response to the first application of maximal concentrations of muscarine ( 10 or $50 \mu \mathrm{M}$ ) varied from cell to cell, and was as fast as $1.9 \mathrm{sec}^{-1}$, or as slow as $0.34 \mathrm{sec}^{-1}$. The average rate constant was $0.703 \pm 0.283 \sec ^{-1}(n=42)$ (mean $\pm \mathrm{SD}$, $n=$ number of experiments) (time constant, $1.4 \mathrm{sec}$ ). This rate should be compared to that for activation of the $G$ proteingated channel, $I_{\mathrm{K}(\mathrm{ACh})}$, in atrial myocytes $\left(1.54 \mathrm{sec}^{-1}\right.$ according to Yatani and Brown, 1989 , or $>5 \mathrm{sec}^{-1}$ estimated from Hartzell et al., 1991).

In a two-state system, the extent of inhibition is $\alpha_{1} /\left(\alpha_{1}+\beta_{1}\right)$. Muscarine could be causing $I_{\mathrm{M}}$ inhibition by increasing the rate of entrance into $\left(\alpha_{1}\right)$, or decreasing the rate of exit from $\left(\beta_{1}\right)$, an inhibited pool of channcls. In the first casc the rate of inhibition $\left(\alpha_{1}+\beta_{1}\right)$ will increase with the extent of inhibition, while in the latter the rate of inhibition will decrease. Figure $3 A$ shows the response to different concentrations of agonist. With higher concentrations of agonist there was more M-current inhibition and the rate was faster (see also Lopez, 1992). Additionally, the delay of the response decreased as the rates of inhibition became faster. The rate of inhibition became systematically slower with repeated agonist applications, making it possible to obtain different rates of inhibition in response to the same concentration of agonist. The relation between rate and degree of inhibition held regardless of the concentration of agonist used. Thus, agonistmediated $I_{\mathrm{M}}$ inhibition can be treated kinetically as a Markov process in which the agonist increases the forward rate of inhibition.

The inset of Figure $3 B$ shows the response to 1 and $30 \mathrm{sec}$ applications of $10 \mu \mathrm{M}$ muscarine. There was a latency of approximately $4.5 \mathrm{sec}$ in the initiation of recovery after the agonist application was terminated. The rate constant of recovery was $0.046 \pm 0.013 \mathrm{sec}^{-1}(n=43)$ (time constant, $\left.21.7 \mathrm{sec}\right)$, and the rate constant of recovery from overrecovery was $0.013 \pm 0.005$ $\sec ^{-1}(n=32)$ (time constant, $\left.76.9 \mathrm{sec}\right)$. The unbinding of muscarine from the receptor is unlikely to be rate limiting, because the concentration that produces $50 \%$ of maximal inhibition is on the order of 0.5-1.0 $\mu \mathrm{M}$ (Adams et al., 1982b; Lopez, 1992), and, assuming a binding rate of at least $3 \cdot 10^{7} \mathbf{M}^{-1} \mathrm{sec}^{-1}$, it can be calculated (Jones, 1992) that the time constant for unbinding of muscarine would be at least $\sim 70 \mathrm{msec}\left(\right.$ rate $\sim 15 \mathrm{sec}^{-1}$ ).

If there are only two pools of M-channels (Fluent and Inhibited) in equilibrium,

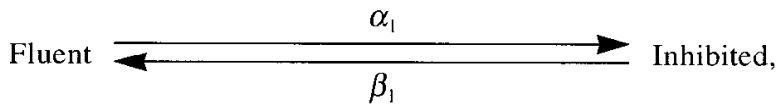

where Fluent is the pool of active (conducting) channels, the extent of overrecovery will be related to its rate by an equation of the form

$$
I / I_{\max }=1-\alpha_{1} /(\text { rate of recovery), }
$$

where $\alpha_{1}$ is the forward rate constant, and the rate constant of recovery is $\alpha_{1}+\beta_{1}$. Since the agonist increases the forward rate (see above), in the simplest case the rate of termination of inhibition should increase as the extent of overrecovery increases. For instance, consider the hypothetical case in which $I_{\mathrm{M}}$ inhibition is mediated by a phosphorylation event. In this situation there are two populations of M-channels: phosphorylated (Inhibited) and nonphosphorylated (Fluent). The agonist could increase the current by stimulating a phosphatase, increasing $\beta_{1}$ and, in consequence, the rate of recovery. This could be an 
Table 1. Kinetic parameters of $M$-current modulation

\begin{tabular}{|c|c|c|c|c|}
\hline & Control & 4-BPB & Quinacrine & NDGA \\
\hline Rate constant of inhibition $\left(\mathrm{sec}^{-1}\right)$ & $0.70 \pm 0.28(42)$ & $0.56 \pm 0.29(22)$ & $0.25 \pm 0.05(4)$ & $0.37 \pm 0.09(3)$ \\
\hline Rate constant of manifestation of overrecovery $\left(\mathrm{sec}^{-1}\right)$ & $0.051 \pm 0.006(8)$ & - & - & - \\
\hline Rate constant of recovery ( $\mathrm{sec}^{1}$ ) & $0.046 \pm 0.013(43)$ & $0.010 \pm 0.006(22)$ & $0.0075 \pm 0.003(4)$ & $0.029 \pm 0.003(3)$ \\
\hline Extent of inhibition (\%) & $85.1+7.7(42)$ & $80.8+9.1(22)$ & $85.0+9.3(4)$ & $82.8 \pm 10.7(3)$ \\
\hline Extent of overrecovery (\%) & $58.9 \pm 26.0(42)$ & - & - & $25.6 \pm 5.7(3)$ \\
\hline
\end{tabular}

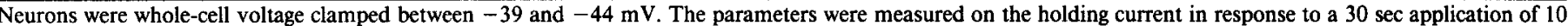

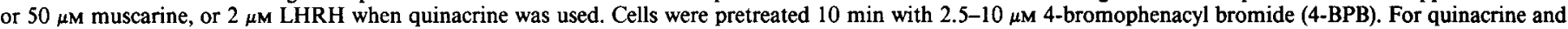

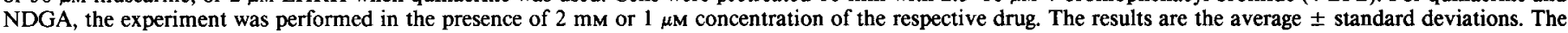
number of experiments is given in parentheses.

example in which only two pools of M-channels will suffice to explain the overrecovery.

In Figure $3 B$ the recovery phase after a $1 \mathrm{sec}$ application of muscarine has been scaled and superimposed to the recovery phase after a $30 \mathrm{sec}$ agonist application in the same neuron, which made the current more than $60 \%$ bigger at the peak of overrecovery (inset in Fig. $3 B$ ). Visual inspection of this plot indicates that the differences in the recovery phase were minimal. In this example, the recovery phase was slightly faster after a $1 \mathrm{sec}$ application that did not causc overrecovery (dotted lines in Fig. 3B), contrary to the predictions of the simple two-pool model. Figure $3 D$ shows a plot of the extent versus the rate constant of overrecovery. The extent of overrecovery was varied by changing the duration of agonist application (open circles), or the agonist concentration (solid circles). Although the scatter of the data is considerable, it is safe to conclude that rate and extent of overrecovery are independent.

To explore the effect of the agonist on the overrecovered current, a second application of agonist at the peak of overrecovery was delivered. In Figure $3 C$ the recovery phase of the first and second responses to muscarine have been scaled and superimposed. Both presented comparable rates. The extent of inhibition relative to the preagonist current levels was not affected significantly $(78.4 \pm 9.9 \%, n=6$; see Table 1$)$. The rate constant of inhibition changed from $0.61 \pm 0.19$ to $0.38 \pm 0.19$ $\sec ^{-1}(n=6)$, similar to the change in rate constant when the second application was made after overrecovery was over (from $0.58 \pm 0.13$ to $0.40 \pm 0.10 \mathrm{sec}^{-1}, n=10$ ).

Thus, no evidence for the agonist affecting the rate of recovery was found. It is therefore concluded that the rate of recovery represents the basal rate of exit from the inhibited state.

\section{There is more overrecovery at hyperpolarized potentials}

To follow the effects of muscarine at different potentials, current relaxations were evoked in response to hyperpolarizing voltage steps. Figure $4 A$ compares the time course of the muscarinic effect in the holding current at $-39 \mathrm{mV}$ (open circles), at the beginning (solid circles), and at the end of a $1 \mathrm{sec}$ voltage step to $-59 \mathrm{mV}$ (triangles). The extent of inhibition and overrecovery were similar when measured at the holding potential or at the beginning of the voltage step. In contrast, the overrecovery (measured relative to the preagonist current levels at the respective time points) was about twofold larger at the end than at the beginning of the voltage jump, while the extent of inhibition was comparable (see Fig. $4 C$ and legend). This could indicate the participation of a different conductance that is inhibited to the same extent as $I_{\mathrm{M}}$ by muscarine, and undergoes overrecovery with the same time course as the M-current; or it could be due to changes in M-current kinetics (see below).

In the simplest case, the size of the current is equal to the product of the number of channels $(N)$, single-channel conductance $(i)$, and probability of the channel being open $\left(p_{o}\right)$. The probability of the $\mathrm{M}$-channel being open depends on voltage. For instance, a shift of $-15 \mathrm{mV}$ in the activation curve could cause a $60 \%$ increase in $I_{M}$, along with a change in M-current relaxation kinetics.

Figure $4 D$ shows the scaled relaxations during control and overrecovery. Also, scaled relaxations evoked by voltage steps to -49 and $-59 \mathrm{mV}$ have been included in Figure $4 E$ for comparison. In $64 \%$ of the cells studied there was a slight and reversible change in the kinetics of the deactivation relaxation during overrecovery, making the relaxation apparently slower (Marrion et al., 1991) (Fig. 4D). The time to reach 70\% of the final current in relaxations evoked by 1 sec steps to $-59 \mathrm{mV}$ was $112.0 \pm 30.6 \mathrm{msec}$ during overrecovery, and $103.9 \pm 27.9$ $\mathrm{msec}$ in control $(n=22)$. The difference on the means was significant at the 0.00004 level (paired $t$ test). Since the dominant time constant changes $e$-fold every $23 \mathrm{mV}$ (Marrion et al., 1992), the changes in relaxation kinetics could be accounted for by a shift of less than $-3 \mathrm{mV}$, which falls short of the $-15 \mathrm{mV}$ shift required to explain the $60 \%$ increase in $I_{\mathrm{M}}$ during overrecovery.

\section{Arachidonic acid enhances $\mathrm{I}_{M}$ in a dose-dependent manner}

There is evidence suggesting that arachidonic acid (AA) may be involved in overrecovery. AA enhances $I_{\mathrm{M}}$ in bullfrog (Bosma et al., 1991) and hippocampal neurons (Schweitzer et al., 1990, 1993), and the enhancement is prevented by blockers of the lipoxygenase pathway in both preparations (Schweitzer et al., 1990, 1993; Yu et al., 1991). There are two potential problems that may be encountered when studying the effects of AA. One is the degradation of cell integrity via free oxygen radicals (Chan and Fishman, 1985) and the other is the decline of AA concentration due to its adsorption to the recording chamber (Samples et al., 1989). The first problem was prevented by substituting manganese (which has oxygen radical scavenging properties; Kono et al., 1976) for calcium. The adsorption problem was minimized by positioning a suction pipette near the neuron under study to accelerate the exchange of solutions.

Figure $5 A$ shows the increase in $I_{\mathrm{M}}$ produced by $20 \mu \mathrm{M} \mathrm{AA}$ in manganese Ringer (see Materials and Methods). In manga- 

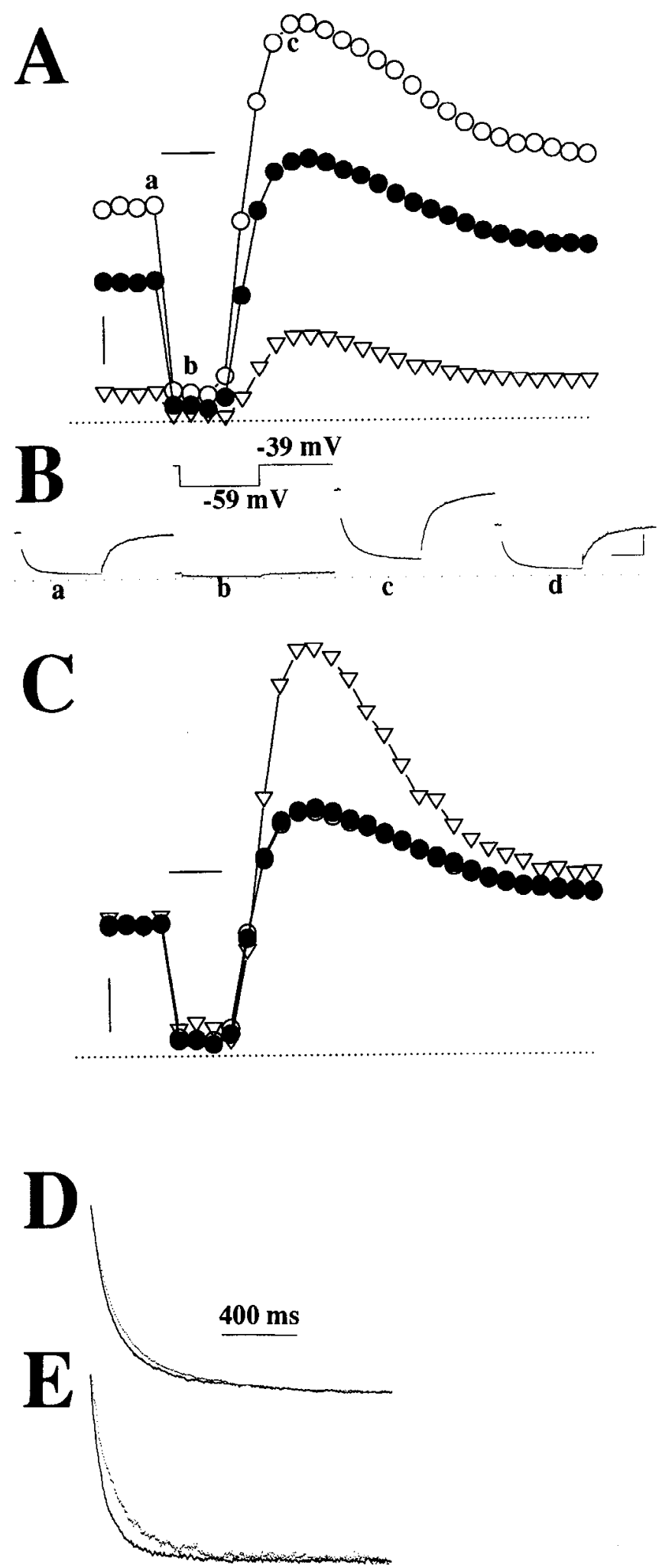

Figure 4. Overrecovery was more prominent at a more hyperpolarized potential. $A$. Time course of the response to $30 \mathrm{sec}$ application of 10 $\mu \mathrm{M}$ muscarine (horizontal bar) in a neuron voltage clamped at $-39 \mathrm{mV}$. The vertical bar represents $0.3 \mathrm{nA}$, and the horizontal dotted line indicates zero current level. $\mathbf{M}$-current relaxations were evoked every 10 sec in response to $1 \mathrm{sec}$ jumps to $-59 \mathrm{mV}$. The current was measured at the holding potential $(O)$, at the beginning of the voltage step (O), and at the end of the step $(\nabla)$. The time course was similar for the three measurements. $B$, Current traces at the points indicated in $A$, except trace $d$, which was recorded $410 \mathrm{sec}$ after removal of agonist. $a$, Control; nese Ringer, the extent of overrecovery evoked by $2 \mu \mathrm{M}$ LHRH was $46.2 \pm 20.2 \%(n=7)$, smaller than in response to muscarine in normal Ringer. $I_{\mathrm{M}}$ enhancement produced by AA was reversible and dose dependent (Fig. $5 B$ ). The maximum enhancement was estimated to be $49.3 \pm 6.7 \%$, and the concentration producing $50 \%$ of the maximum was estimated to be $2.8 \pm 1.8$ $\mu \mathrm{M}$ (see legend of Fig. $5 B$ ). The current recovered to a level smaller than control, suggesting that, in addition to enhancing the current, AA triggered other pathways that lead to $I_{M}$ inhibition (Béhé et al., 1992).

AA could be increasing the current by activating a conductance unrelated to the M-current, or by revealing a pool of $\mathrm{M}$-channels different than the one manifested during overrecovery. If AA is revealing the same pool of channels that appears during overrecovery, in the presence of AA the M-current should be inhibited by agonist, and the overrecovery should be largely occluded. Two micromolar LHRH inhibited $I_{\mathrm{M}}$ by $89.5 \pm 11.6 \%$ $(n=8)$ in the presence of $20 \mu \mathrm{M} \mathrm{AA}$, and the current recovered only to $\sim 90 \%$ of the preagonist level (e.g., no overrecovery was observed) (not shown). However, in this series of experiments the profile of the response to agonist was altered. After a partial recovery, the current became progressively smaller, and a slowly inactivating outward current revealed by hyperpolarizing voltage pulses became gradually bigger (not shown).

AA caused a very small and reversible change in deactivation relaxation kinetics (Fig. $5 \mathrm{C}$ ), but in contrast to the alteration during overrecovery, the relaxation became apparently faster. The time to reach $70 \%$ of the final relaxation was $95.4 \pm 12.0 \%$ $(n=31)$ of control $(102.5 \perp 28.0 \mathrm{msec}$ and $95.9 \pm 21.5 \mathrm{mscc}$ in control and in the presence of AA, respectively). The difference of the means was significant at the 0.006 level (paired $t$ test).

Figure $5 D$ shows the current-voltage relationship ( $I-V)$ measured at the end of $1 \mathrm{sec}$ voltage steps in the presence (solid circles) and in the absence (open circles) of $10 \mu \mathrm{M} \mathrm{AA}$. The $I-$ $V$ relationship was practically linear from $-75 \mathrm{mV}$ down to $-115 \mathrm{mV}$. In the presence of AA the slope of this linear portion was steeper, and both $I-V$ relationships crossed over around $-75 \mathrm{mV}$, indicating that $\mathrm{AA}$ was activating another conductance.

The rate of recovery of $\mathrm{I}_{A}$, an arachidonic acid-sensitive current, is similar to the rate of recovery of $\mathrm{I}_{M}$ from overrecovery

The hypothesis that AA is produced in rcsponse to muscarine is very plausible, because it has been found that carbachol (a muscarinic agonist) stimulates AA release from A9 L cells trans-

$b$, peak inhibition; $c$, peak overrecovery; $d$, recovery. $C$, The data in $A$ have been normalized to the current at the preagonist level (same symbols as in A). Horizontal bar is $40 \%$ of control. At the peak of overrecovery, the current increased by $208 \%$ at $-59 \mathrm{mV}$, and $88 \%$ at -39 $\mathrm{mV}$. In 13 neurons the extent of inhibition was (as \%) $86.8 \pm 5.8,92.3$ \pm 5.7 , and $86.8 \pm 14.5$ (mean $\pm \mathrm{SD}$ ) at the holding potential $(-39$ $\mathrm{mV}$ ), at the beginning of the voltage step to $-59 \mathrm{mV}$, and at the end of the $1 \mathrm{sec}$ voltage step to $-59 \mathrm{mV}$, respectively. The extent of overrecovery was (as \%) 61.7 $\pm 17.3,67.8 \pm 18.0$, and 141.4 \pm 44.0 , respectively. $D$, The deactivation kinetics changed slightly during overrecovery in a reversible manner, making the relaxations apparently slower. Current relaxations evoked by a pulse to $-59 \mathrm{mV}$ were scaled and superimposed. Solid line, control; dotted line, peak overrecovery. Same cell as in $A$. $E$, Comparison of deactivation kinetics at $-49 \mathrm{mV}$ (dotted line) and $-59 \mathrm{mV}$ (solid line). Different cell than in $A$. 


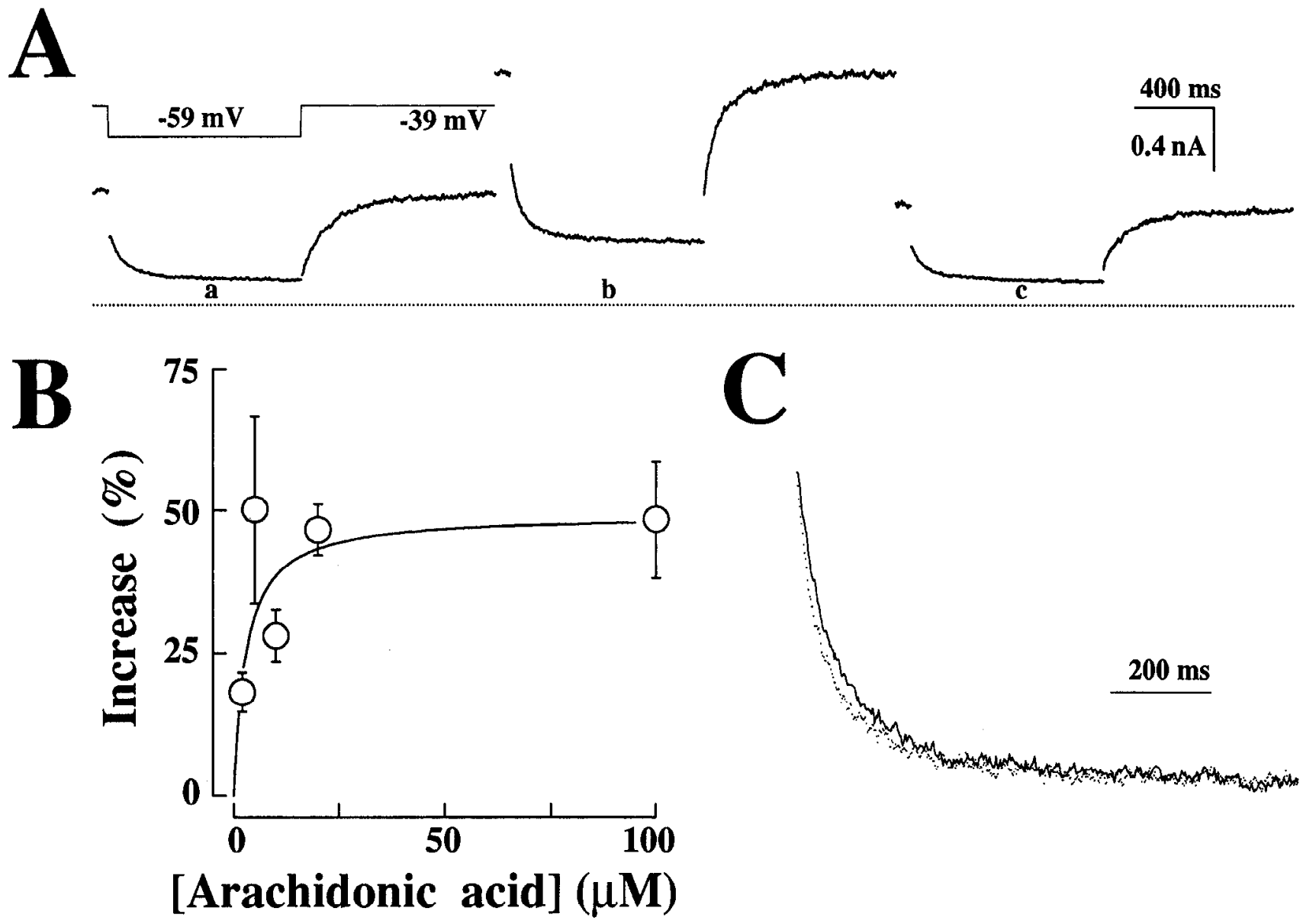

D
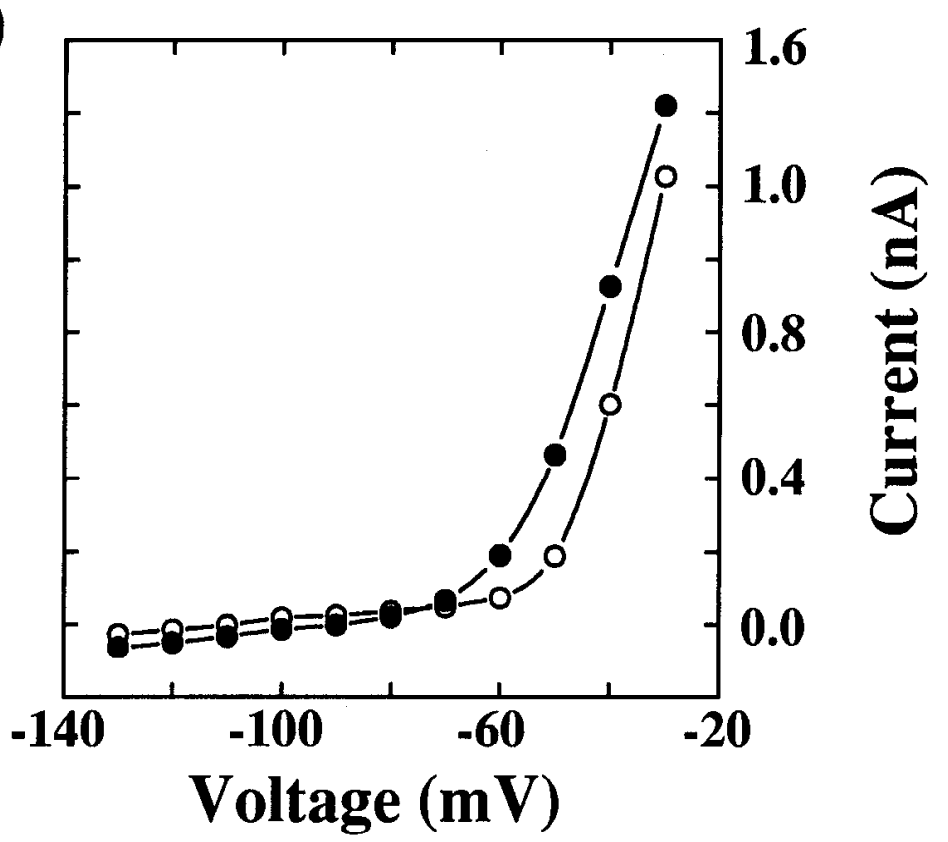

Figure 5. Arachidonic acid augments $I_{\mathrm{M}} . A$, Effect of $20 \mu \mathrm{M} \mathrm{AA}$ in a neuron voltage clamped at $-39 \mathrm{mV}$. $I_{\mathrm{M}}$ relaxations were revealed by 1 sec voltage steps to $-59 \mathrm{mV}$. $I_{\mathrm{M}}$ enhancement induced by AA was rcversible. After $60 \mathrm{sec}$, bovine serum albumin (1.0 mg/ml) was used to help remove AA from the bath. The experiment was performed in manganese Ringer, which was made by substituting $\mathrm{Mn}^{2+}$ for $\mathrm{Ca}^{2+}$, and adding 1 mM TEA (a potassium channels blocker), $0.2 \mathrm{~mm} d$ - tubocurarine (a blocker of some calcium-activated potassium channels), and $200 \mathrm{~nm}$ TTX (a sodium channel blocker). AA was bath applied, and the solution was forced into the cell by a suction pipette positioned $\sim 150 \mu \mathrm{m}$ away. This setup was important to reach a rapid steady state response to AA. $a$, control; $b$, after $60 \mathrm{sec}$ in the presence of AA; $c$, recovery (after 80 sec of AA removal). 


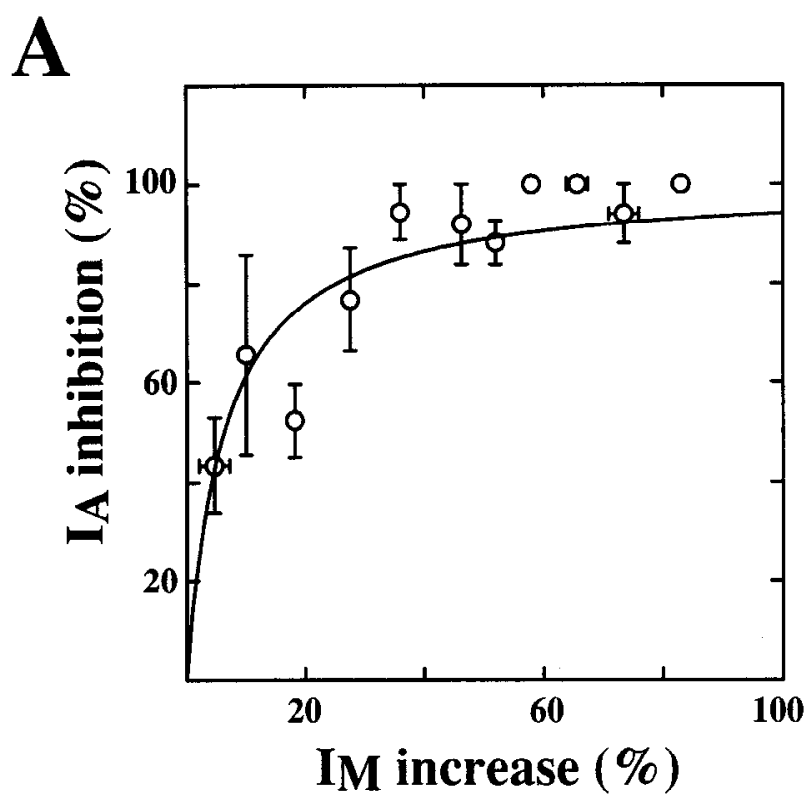

B<smiles>CCCCC</smiles>
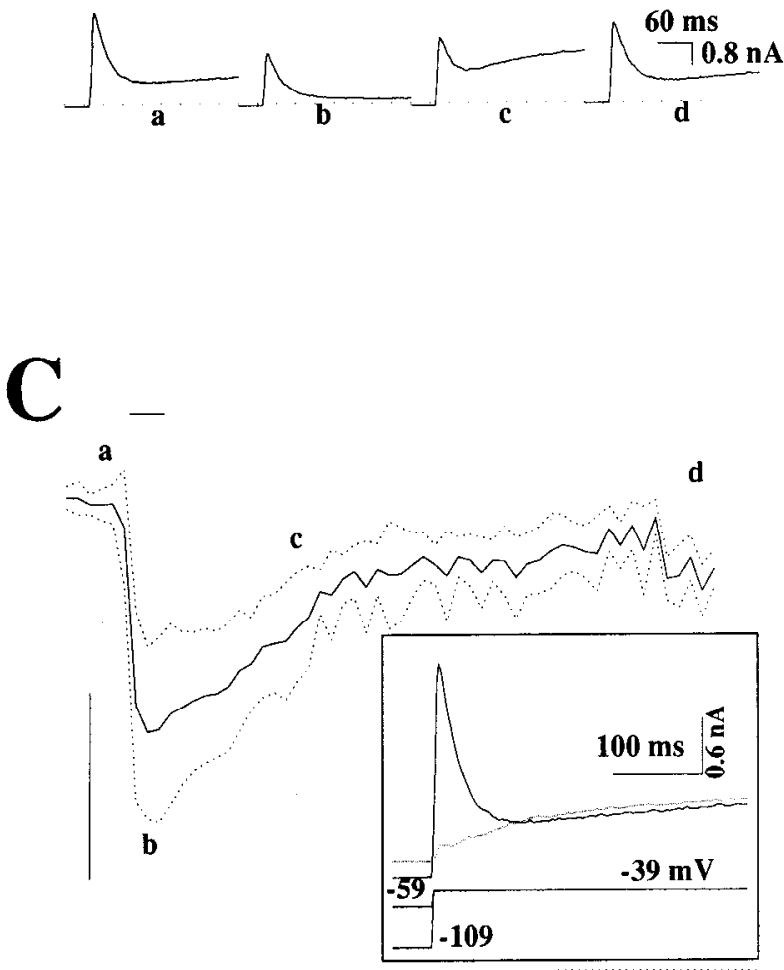

fected with $\mathrm{ml}$ or $\mathrm{m} 3$ muscarinic receptor genes, but not from cells transfected with the $\mathrm{m} 2$ or $\mathrm{m} 4$ muscarinic receptor genes (Conklin et al., 1988). In addition, the endogenous $I_{\mathrm{M}}$ of NG10815 cells is inhibited by carbachol in cells transfected with $\mathrm{ml}$ or $\mathrm{m} 3$ muscarinic receptor genes, but not in cells transfected with $\mathrm{m} 2$ or $\mathrm{m} 4$ muscarinic receptor genes (Fukuda et al., 1988). However, an assessment of AA production in response to muscarine in bullfrog neurons is necessary. In these neurons, AA inhibits the A-current $\left(I_{A}\right)$ (Villarroel, 1993), a different voltagedependent transient potassium current. The $\mathrm{IC}_{50}$ for $I_{\mathrm{A}}$ inhibition and M-current increase are comparable, on the order of 2 $\mu \mathrm{M}$. Concentrations of AA that increase $I_{\mathrm{M}}$ more than $40 \%$ reduce $I_{\mathrm{A}}$ more than $80 \%$ (Fig. $6 A$ ). Figure $6 B$ shows that muscarine reduced $I_{\mathrm{A}}$. Similar results were obtained in response to $2 \mu \mathrm{M}$ LHRH. Thus, these observations are compatible with the hypothesis that the agonist stimulates AA release.

In a previous section it was concluded that the fast rate (rate of recovery from inhibition $\sim 0.05 \mathrm{sec}^{-1}$ ) was related to the rate of exit from the Inhibited pool. Consequently, the recovery from overrecovery (rate $\sim 0.01 \mathrm{sec}^{-1}$ ) should be dominated by the enhancing pathway. If the hypothesis that muscarine triggers AA release causing augmentation of $I_{\mathrm{M}}$ and reduction of $I_{\mathrm{A}}$ is correct, then the time course of recovery of $I_{\mathrm{M}}$ from overrecovery, and recovery of $I_{\mathrm{A}}$ from inhibition should be comparable.

Figure $6 C$ shows the averaged time course of $I_{\mathrm{A}}$ inhibition in response to a $30 \mathrm{sec}$ application of $10 \mu \mathrm{M}$ muscarine. The rate constant of recovery of $I_{\mathrm{A}}$ from inhibition was $0.0092 \pm 0.001$ $\sec ^{-1}(n=10)$, similar to the rate constant of recovery of $I_{\mathrm{M}}$ from overrecovery (Table 1). However, the rate constant of inhibition was $0.24 \pm 0.01 \mathrm{sec}^{-1}(n=10)$, about five times faster than the rate of manifestation of overrecovery (Table 1), and the extent of $I_{\mathrm{A}}$ inhibition $(48.5 \pm 22.7 \%, n=10)$ was insufficient to account for $60 \%$ overrecovery (see Fig. $6 A$ ).

Figure 6. Time course of A-current modulation by muscarine. $A, \mathrm{Re}-$ lation between $I_{\mathrm{M}}$ increase and $I_{\mathrm{A}}$ reduction by AA. Error bars are standard errors of the mean. The solid line is the empirical relation \% $I_{\mathrm{A}}$ inhibition $=M \cdot 100 /(M+6.3)$, where $M$ is the increase on $I_{\mathrm{M}} . B$, Raw data of a typical response to muscarine at the time points indicated in $C$. $C$, The continuous line shows the average response to a $30 \mathrm{sec}$ application of $10 \mu \mathrm{M}$ muscarine (horizontal bar) on $I_{\mathrm{A}}(n=10)$. Dotted lines are the means \pm standard deviation. The vertical bar corresponds to $40 \%$ of $I_{\mathrm{A}}$ current. $I_{\mathrm{A}}$ was estimated at $-39 \mathrm{mV}$ as the peak outward current evoked after a deinactivating prepulse to $-110 \mathrm{mV}$ after subtracting the M-current-activating relaxation evoked with a prepulse to $-60 \mathrm{mV}$ (see inset). Voltage jumps were delivered every $10 \mathrm{sec}$. The rate constant of $I_{\mathrm{A}}$ inhibition was $0.24 \pm 0.01 \mathrm{sec}^{-1}(n=10)$, and the rate constant of recovery was $0.0092 \pm 0.001 \sec ^{-1}(n=10)$.

Zero current level is indicated by the dotted line. $B$, Dose-response relation of AA-induced $I_{\mathrm{M}}$ increase in manganese Ringer. $I_{\mathrm{M}}$ was quantified as the size of the deactivation relaxation evoked by $1 \mathrm{sec}$ steps to $-59 \mathrm{mV}$ from a holding potential of $-39 \mathrm{mV}$. The hyperbolic relation max $\cdot[\mathrm{AA}] /$ $\left([\mathrm{AA}]+\mathrm{IC}_{50}\right)$ was fitted to the data, with $\max =49.32 \pm 6.71 \%$ and $\mathrm{IC}_{50}=2.82 \pm 1.83 \mu \mathrm{M}$. The circles are the average of the result of (from lower to higher $[\mathrm{AA}]) 6,4,11,15$, and 4 experiments. Error bars are standard errors of the mean. Note that the second point from the left is the average of four experiments; therefore, it will have a smaller weight in the estimation of the parameters $\mathrm{IC}_{50}$ and max. $C$, The deactivation kinetics changed slightly in the presence of $\mathrm{AA}$ in a reversible manner, making the current apparently faster. Current relaxations evoked by a pulse to - $59 \mathrm{mV}$ were scaled and superimposed. Solid line, Control; dotted line, in the presence of $20 \mu \mathrm{M}$ AA. Samc cell as in $A$. $D$, Current-voltage relationship in control $(O)$ and in the presence of $10 \mu \mathrm{M} \mathrm{AA}(O)$. Currents were measured at the end of a $1 \mathrm{sec}$ pulse to the test potential. Different cell than in $A$. 

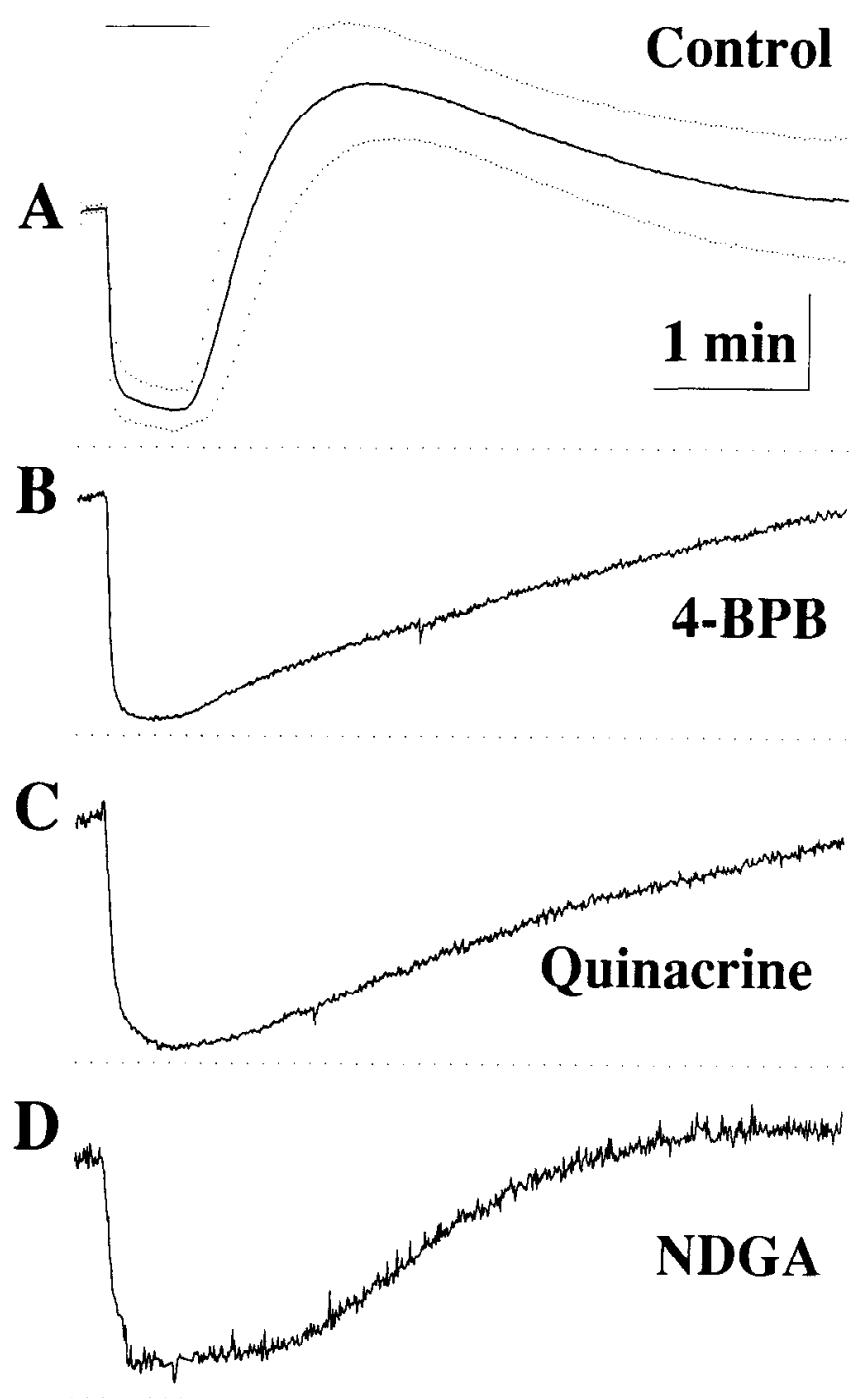

Figure 7. Time course M-current modulation in response to $30 \mathrm{sec}$ application of agonist under different treatments. The dotted horizontal line represents 0 current level. Each dot is $6 \mathrm{sec}$ apart. $A$, Control. Average response of 38 neurons to 10 or $50 \mu \mathrm{M}$ muscarine on the normalized holding potential (between -39 and $-44 \mathrm{mV}$ ). Dotted lines are the mean \pm standard deviation. Vertical bar represents $40 \%$ of holding current. $B$, Response after treatment with 4-BPB. The neuron was incubated $10 \mathrm{~min}$ in the presence of $10 \mu \mathrm{M} 4-\mathrm{BPB}$, the drug was washed, and after $10 \mathrm{~min}$ the response to $10 \mu \mathrm{M}$ muscarine was monitored. Overrecovery was totally suppressed and the recovery phase became very slow (see Table 1). Vertical scale bar in A corresponds to $0.62 \mathrm{nA}$. $C$, Response to $2 \mu \mathrm{M} \mathrm{LHRH}$ in the presence of $2 \mathrm{~mm}$ quinacrine. Vertical bar in $A$ corresponds to $0.55 \mathrm{nA}$. $D$, Response to $10 \mu \mathrm{M}$ muscarine in the presence of $1 \mu \mathrm{M}$ NDGA. Vertical bar in $A$ corresponds to $0.41 \mathrm{nA}$.

\section{Inhibitors of the arachidonic acid cascade make the recovery} phase very slow

The picture emerging from the data presented so far is that the agonist may trigger two parallel pathways with opposing effects, one which enhances and another that inhibits $I_{\mathrm{M}}$. The inhibition prevails over the enhancement, but the enhancing substance outlives the inhibitory one, allowing a time window in which the enhancing substance is present in absence of the inhibitory second messenger, causing overrecovery. According to this model, the rate of recovery $\left(\sim 0.05 \mathrm{sec}^{-1}\right)$ will be approximately the sum of the rate of disappearance of the enhancing substance $\left(\sim 0.01 \mathrm{sec}^{-1}\right)$ and the rate of disappearance of the inhibitory one.

Theoretically, the time window in which the enhancing substance predominates can be eliminated by preventing the production of such a substance or by increasing the lifetime of the inhibitory intermediary. Both cases can be distinguished kinetically. In the first case the rate of recovery will be changed slightly, while in the latter the recovery rate will become very slow [an extreme case is the occlusion of overrecovery when $I_{\mathrm{M}}$ is inhibited irreversibly by muscarine in cells dialyzed with GTP $\gamma$ S (e.g., Pfaffinger, 1988; Lopez and Adams, 1989)]. The effects on the time course of modulation of several pharmacological agents known to interfere with the AA cascade were examined.

There are thrce major pathways for AA metabolism: cyclooxygenase, lipoxygenase, and epoxygenase (Needleman et al., 1986). Neither the cyclooxygenase inhibitor indomethacin nor the epoxygenase inhibitor clotrimazole prevented overrecovery. The current was reduced by $74.8 \pm 9.7 \%(n=4)$ and by $72.3 \pm$ $6.8 \%(n=3)$, and overrecovery was $71.4 \pm 17.5 \%(n=4)$ and $63.3 \pm 7.8 \%(n=3)$ in the presence of $10 \mu \mathrm{M}$ indomethacin and $10 \mu \mathrm{M}$ clotrimazole, respectively. In the presence of indomethacin the recovery phase was oscillatory in three of four cells (not shown). While the significance of this observation is unclear, it may indicate that an energy-requiring process is taking place during $I_{\mathrm{M}}$ modulation.

In neurons pretreated $10 \mathrm{~min}$ with $2.5-10 \mu \mathrm{M}$ 4-bromophenacyl bromide (4-BPB), a nonspecific irreversible phospholipase $\mathrm{A}_{2}$ inhibitor (Volwek et al., 1974), the rate and extent of inhibition were not significantly affected, but the rate of recovery was very slow and variable (Fig. 7B, Table 1). However, 4-BPB treatment did not affect AA action. Twenty micromolar AA increased $I_{\mathrm{M}}$ by $45.3 \pm 15.6 \%(n=3)$.

In the presence of the reversible nonspecific phospholipase $A_{2}$ inhibitor quinacrine (Blackwell and Flower, 1983), LHRH was used because muscarine did not produce any effect, presumably because receptor binding was inhibited (O'Donnell and Howlett, 1991). Quinacrine did not prevent overrecovery at concentrations equal to or below $500 \mu \mathrm{M}(n=10)$. This contrasts with the prevention of somatostatin-mediated $I_{\mathrm{M}}$ enhancement in hippocampal neurons by low micromolar concentrations (Schweitzer et al., 1990, 1993). However, 2 mm quinacrine suppressed overrecovery (Fig. $7 \mathrm{C}$ ) in a reversible manner (not shown). At this concentration the continuous presence of quinacrine induced responses resembling those of muscarine. It caused an initial reduction of $I_{\mathrm{M}}$ followed by a transient enhancement, and finally $I_{\mathrm{M}}$ reached a stable level that was smaller than control (not shown).

In the presence of $1 \mu \mathrm{M}$ nordihydroguaiaretic acid (NDGA), a lipoxygenase inhibitor (Egan and Gale, 1985), overrecovery was partially suppressed (Fig. $7 D$ ). The prevention of overrecovery by these treatments was accompanied by a dramatic slowing of the recovery rate (Fig. 7, Table 1). These results indicate that the main mechanism of action of these pharmacological agents is to prolong the lifetime of the Inhibited pool of M-channels. However, the possibility that they are simultaneously blocking the production of the putative enhancing substance cannot be ruled out.

\section{Discussion}

The time course of M-current modulation distinguishes two processes, one enhancing and one inhibitory. The rate of inhi- 
Table 2. Summary of evidence for the second messenger mediating overrecovery

\begin{tabular}{|c|c|c|}
\hline & Arachidonic acid & Calcium $^{a}$ \\
\hline It is produced in response to muscarine or LHRH & Yes $^{b}(?)$ & Yes \\
\hline It is produced at appropriate rate & Yes $^{b}(?)$ & Yes $^{c}$ \\
\hline It is produced in sufficient amount & $\mathbf{N o}^{b}(?)$ & ? (Yes) \\
\hline It is removed at appropriate rate & $\operatorname{Yes}^{b}(?)$ & $\mathrm{Yes}^{d}$ \\
\hline Extent of enhancement is appropriate & Yes & Yes \\
\hline Minimal change in relaxation kinetics & Faster & Slower \\
\hline Enhanced current can be inhibited by agonist & Yes & No (?) \\
\hline Enhancement can be prevented & Lipoxygenase inhibitors ${ }^{e}$ & Very high concentrations of BAPTA \\
\hline $\begin{array}{l}\text { Time to recover to } 50 \% \text { after preventing } \\
\text { enhancement is less than } 35 \mathrm{sec}\end{array}$ & No & No \\
\hline
\end{tabular}

Evidences conflicting with the participation in overrecovery of the given substance are in boldface.

${ }^{a}$ Marrion et al. (1991).

${ }^{h}$ Based on $I_{A}$ modulation.

' Pfaffinger et al. (1988).

"See Pfaffinger et al. (1988) for contrasting result.

'Yu et al. (1991).

bition is 15 times faster than the rate of manifestation of overrecovery, indicating that the probability of the M-current being inhibited is higher than the probability of being enhanced. Arachidonic acid is a good candidate for a precursor of the putative second mcssengcr mediating overrccovery bccausc it enhances the M-current in a dose-dependent manner to an appropriate degree. The concentration necessary to produce $50 \%$ of the effect is on the order of $3 \mu \mathrm{M}$, well within the order of the $K_{\mathrm{M}}$ for the enzymes involved in the AA cascade (Needleman et al., 1986). Another possible second messenger is calcium (Marrion et al., 1991). The evidence for the participation of AA and calcium in overrecovery is summarized in Table 2 . The proposal that calcium is mediating overrecovery is compromised because the concentration of BAPTA (a potent calcium chelator) necessary to prevent overrecovery is very high ( $20 \mathrm{~mm}$; Marrion et al., 1991), and the time course of changes in intracellular calcium levels (estimated using fluorescent indicators) does not necessarily parallel overrecovery (Pfaffinger et al., 1988). In this study, the levels of AA were estimated by monitoring $I_{\mathrm{A}}$. Monitoring AA levels from the size of $I_{\mathrm{A}}$ has the drawback that it can give an overestimation if there are other processes reducing this current. However, the calculated equivalent amount of AA produced by muscarine was insufficient to cause $60 \% I_{\mathrm{M}}$ enhancement. It can be argued that $I_{\mathrm{M}}$ is more sensitive to AA released by agonist because $I_{\mathrm{M}}$ colocalizes with the source of AA, therefore experiencing higher local concentrations than $I_{\mathrm{A}}$. Alternatively, it can be argued that the agonist triggers another mechanism that reduces the sensitivity of $I_{\mathrm{A}}$ for AA.

The time course of the recovery phase of $I_{\mathrm{M}}$ from inhibition indicates that the inhibitory pathway is terminated about three times faster than the enhancing pathway. The agonist may be triggering two pathways leading to the production of an inhibitory and an enhancing intermediate. From the data in Table 1 it can be estimated that the half-life of the inhibitory substance would be $21 \mathrm{sec}$, and for the enhancing substance would be 53 sec. A prediction from this hypothesis is that blocking the enhancing pathway should prevent overrecovery, leaving inhibition intact, and the time to recover to $50 \%$ of the preagonist level should be about $26 \mathrm{sec}$ (allowing for $5 \mathrm{sec}$ latency in the initiation of recovery). The effect on the time to recover to $50 \%$ of the two phospholipase $A_{2}$ and the lipoxygenase inhibitors tested in this study deviates wildly from this prediction, indicating that the main effect of these agents is to prolong the life of the inhibited pool of M-channels. Therefore, blocking overrecovery does not nccessarily require that therc be two parallel pathways. It is also possible that only one second messenger could alter the equilibrium between three or more pools of channels (see below).

The high quinacrine concentrations needed to block overrecovery and its effects on $I_{\mathrm{M}}$ obscure the significance of its action. However, it is an important result because it indicates that overrecovery can be prevented in a reversible manner. AA increased $I_{\mathrm{M}}$ after treatment with 4-BPB, indicating that 4-BPB was probably preventing AA release. At low concentrations, NDGA is a relatively specific lipoxygenase inhibitor (but see Vacher et al., 1989; Korn and Horn, 1990), suggesting that a lipoxygenase metabolite participates in the termination of inhibition, possibly by altering the function of the G-protein (Scherer and Breitwieser, 1990) involved in inhibition (Pfaffinger, 1988; Brown et al., 1989; Lopez and Adams, 1989; Tokimasa and Akasu, 1990). Taken together, these results suggest that, as found in Aplysia neurons (Carlson and Levitan, 1990), there is a rapid turnover of AA, creating steady state conditions with relatively low concentrations of AA (so $I_{\mathrm{A}}$ can be observed) and relatively high concentrations of a lipoxygenase metabolite, such that under resting conditions the rate of termination of inhibition is fast.

Recently, Akasu et al. (1993) reported that overrecovery was greatly reduced in cells internally perfused with $30 \mu \mathrm{M}$ SM-I, a peptide inhibitor of myosin light kinase (MLCK), suggesting that MLCK may participate in overrecovery. It would be interesting to see if this inhibitor prevents AA-mediated $I_{\mathrm{M}}$ enhancement.

\section{On the origin of overrecovery}

Single-channel data indicate that the M-channel can open in two different modes which include similar subconductance levels (Marrion, 1993). Gating mode 1 is practically voltage independent, while gating mode 2 is voltage dependent. According to Marrion (1993), M-current deactivation will display a fast 
Figure 8. A, A model for $I_{\mathrm{M}}$ modulation. The model proposes that there are three pools of M-channels in equilibrium. The agonist triggers a cascade of events that leads to an increase of the rate transition from the Tacit to the Fluent pool $\left(\alpha_{2}\right)$, and from the Fluent to the Inhibited pool $\left(\alpha_{1}\right)$. It is proposed that arachidonic acid increases the current by stabilizing the Fluent pool. $B$, Simulation of M-current modulation. Simulation of $I_{\mathrm{M}}$ modulation in response to 10,1 , and 0.3 units of agonist. It was assumed that the Tacit pool does not include conducting channels. The dependency of $\alpha_{1}$ and $\alpha_{2}$ on agonist was modeled with the equation $\alpha_{i \text { (agonist) }}=$ $\alpha_{i 0}\left([A] \cdot S+K_{d i}\right) /\left([A]+K_{d i}\right)$, where $S=$ $50, K_{d 1}=0.8$ units, $K_{d 2}=1.0$ units, and $[A]$ is the concentration of agonist in units. The rate constants were (in $\mathrm{sec}^{-1}$ ) $\alpha_{1}=0.0150, \alpha_{2}=0.0010, \beta_{1}=0.0250$, $\beta_{2}=0.0030$, and $\beta_{3}=0.0030$. The remaining rate constant was derived from the others, assuming microscopic reversibility (Onsager, 1931): $\alpha_{3}=$ $\beta_{1} \cdot \beta_{2} \cdot \beta_{3} /\left(\alpha_{1} \cdot \alpha_{2}\right)\left(\right.$ for $\left.[A]=0, \alpha_{3}=0.015\right)$. The two time constants for recovery derived from these rate constants are 19.31 and $97.89 \mathrm{sec}$ (for the explicit solution of a cyclic three-state system see Szabó, 1969; see also Rodiguin and Rodiguina, 1964). $C$, Relation between inhibition and overrecovery from the model, after $30 \mathrm{sec}$ application of different units of agonist. $D$, Simulation of the response to different durations of a maximal concentration of agonist (making $\alpha_{1}=0.75$ and $\alpha_{2}=0.05$ ). The two time constants during inhibition were 1.54 and 20.07 $\mathrm{sec}$. The duration of the application was (from left to right) $1,3,10$, and $30 \mathrm{sec}$. $E$, Relation between overrecovery and duration of agonist application. The relation is equal to the sum of two exponential functions: $175.61-87.04$. $e^{-t / 19.44}+11.6 \cdot e^{-t / 2.08}$.
A
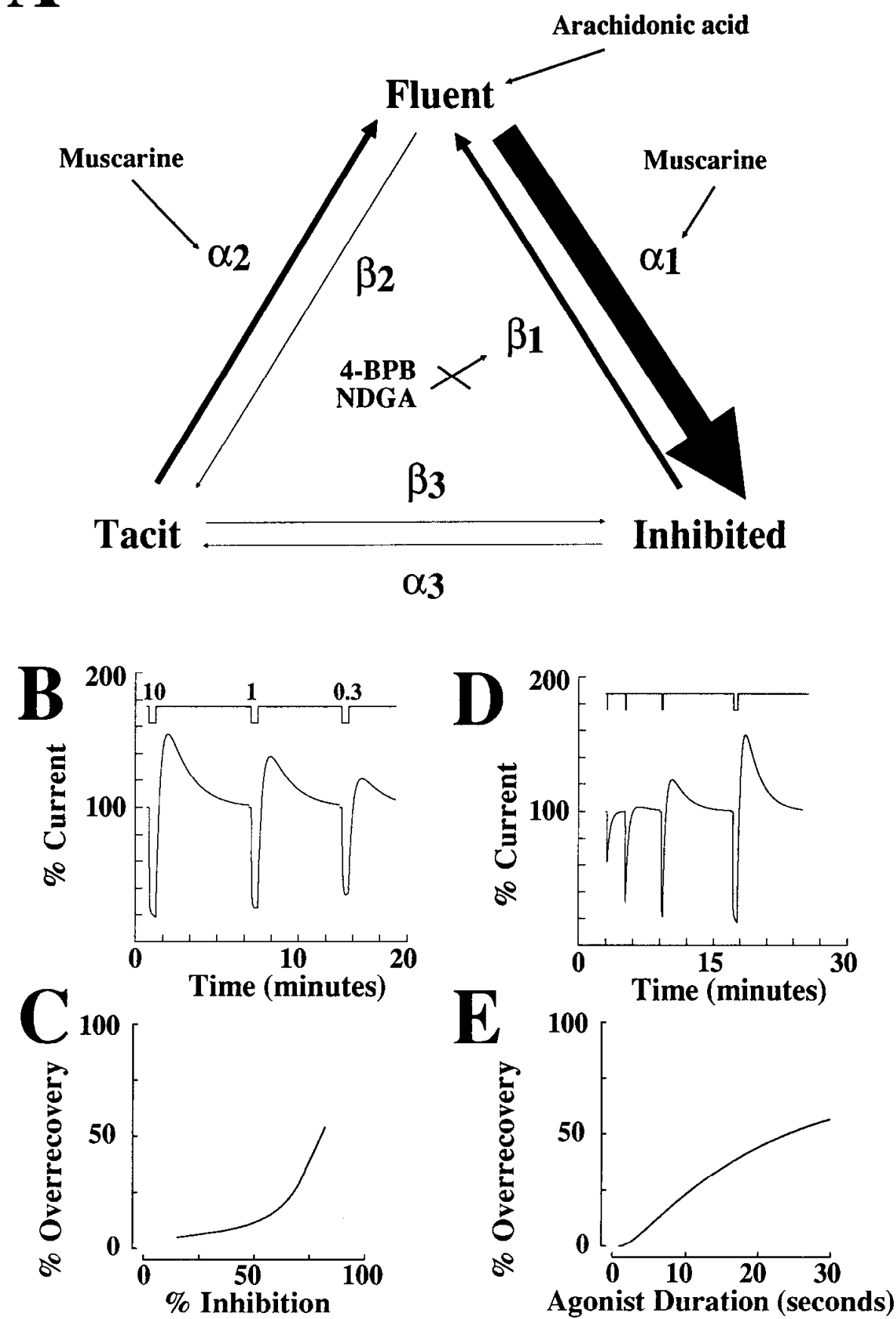

time constant originating from mode 1 gating, and the slower voltage-dependent relaxations arisc principally from mode 2 gating. It has been suggested that the augmentation of the current during overrecovery could result from an increase in mode 2 M-channel gating (Marrion, 1993). Indeed, the slowing on deactivation relaxation kinetics and the larger overrecovery at hyperpolarized potentials could arise if the current deactivates to a lesser extent during the $1 \mathrm{sec}$ hyperpolarizing pulse because the channels enter into a slowly deactivating mode that may correspond to gating mode 2 , or to a slower, as yet unidentified, gating mode.

The lack of relationship between the rate of recovery and extent of overrecovery argues against a simple two-pool model to explain overrecovery (see Results). In addition, the proportion of channels tonically inhibited calculated from the rate of spontaneous reduction in cells dialyzed with GTP $\gamma \mathrm{S}\left(0.009 \mathrm{sec}^{-1}\right)$ (Lopez, 1992) and the rate of recovery $\left(0.046 \mathrm{sec}^{-1}\right)$ is $16 \%$, which is insufficient to account for a $60 \%$ increase in the current during overrecovery. Therefore, there are three alternatives for the origin of overrecovery: (1) there is an increase in the pool of available or Fluent channels originating from a third (noninhibited) pool; (2) there is an increase in $p_{o} \cdot i$ in the available channels, or (3) a new pool of conducting channels is being revealed. The data presented do not distinguish between these 


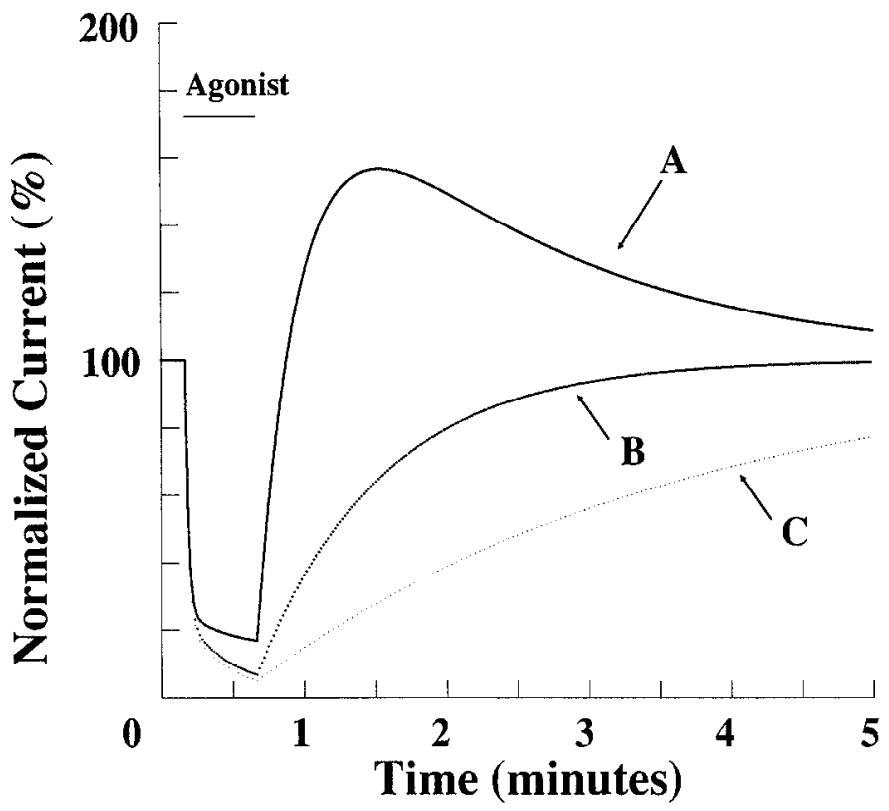

Figure 9. The effect of arachidonic acid metabolism inhibitors was simulated by reducing $\beta_{1}$ to $0.001 \sec ^{-1}(B)$, or reducing $\beta_{1}$ to 0.001 and $\alpha_{1}$ to $0.0015 \mathrm{sec}^{-1}(C) . A$ is a simulation using the same values as in Figure $8 D$. Compared to $A$, the size of the current at steady state was fourfold smaller in $B$ and 1.2-fold smaller in $C$.

alternatives. However, the three situations imply essentially the same thing, namely, that the M-channel exists in equilibrium between three pools, one with low $p_{o} \cdot i$ (that will be referred here as the Tacit pool), another with high $p_{o} \cdot i$ (Fluent pool), and an Inhibited, nonconducting pool (Fig. $8 A$ ). The first alternative [an increase in the pool of available or Fluent channels originating from a third (noninhibited) pool] occurs when the product $p_{o} \cdot i$ of the Tacit pool equals zero.

\section{$A$ model for $M$-current modulation}

It is proposed that there are three pools of channels, Tacit, Fluent, and Inhibited, in equilibrium (Fig. 8A). The product $p_{o}$. $i$ is smaller for channels in the Tacit pool than for channels in the Fluent pool, and is zero for channels in the Inhibited pool because the current can be totally suppressed in cells dialyzed with GTP $\gamma$ S (Pfaffinger, 1988; Brown et al., 1989; Lopez and Adams, 1989).

The model proposes that the agonist causes an increase in the rate of transition from Fluent to Inhibited $\left(\alpha_{1}\right)$, and from Tacit to Fluent $\left(\alpha_{2}\right)$, such that in the presence of the agonist the channels accumulate in the Inhibited pool. $\alpha_{1}$ is much bigger than $\alpha_{2}$ and controls the rate of inhibition, while the rate of manifestation of overrecovery is dominated by $\alpha_{2}$. On removal of the agonist the rate transitions $\alpha_{1}$ and $\alpha_{2}$ return to the original values, and the channels exit the Inhibited pool through two pathways, leading to Fluent and Tacit. The probability of going into the Fluent pool is higher than the probability of entering into the Tacit pool $\left(\beta_{1}>\alpha_{3}\right)$, and the transition from Inhibited to Fluent is faster than the transition from Fluent to Tacit $\left(\beta_{1}\right.$ $>\beta_{2}$ ) so the channels accumulate in the Fluent pool (which conduct more current), causing overrecovery, and, eventually, they return to the original state.

A simulation of modulation using this model is presented in Figure $8 B-E$. The slowing of recovery and suppression of over- recovery observed after treatment with arachidonic acid metabolism inhibitors can be simulated by increasing the lifetime of the Inhibited pool (reducing $\beta_{1}$ ) (Fig. 9). The reduction of $\beta_{1}$ makes the current smaller (not shown). This result is in accordance with the observation that lipoxygenase blockers reduce $I_{\mathrm{M}}$ (Yu et al., 1991).

The model relies on many assumptions, but it does establish an initial quantitative framework to understand the mechanism of M-current modulation, and it describes the time course of modulation. It is therefore useful for testing the effects of different patterns of stimulation on $I_{\mathrm{M}}$, or for improving other models of synaptic integration.

The excitability of neurons depends on the initial conditions of different ionic channels. The initial conditions are controlled mainly by the interplay of internal calcium concentration and membrane potential. The steady state levels of arachidonic acid and its metabolites are likely to have a profound effect on the resting conditions of many ionic conductances and on the dynamics of modulation, adding to the complexity and nonlinearity of synaptic input integration.

\section{Note added in proof}

Recently, Chen et al. (1993) reported that overrecovery is attenuated by intracellular application of $150 \mu \mathrm{M}$ heparin. This observation has been taken as support of the hypothesis that $\mathrm{IP}_{3}$-mediated intracellular calcium release mediates overrecovery, because heparin competitively inhibits the interaction of $\mathrm{IP}_{3}$ with its receptor $\left(K_{I}=2.7 \mathrm{nM}\right)$. Yu et al. (1994) have reported that overrecovery is present in cells dyalized with $20 \mathrm{~mm}$ BAPTA supplemented with $8.47 \mathrm{~mm}$ calcium to obtain $120 \mathrm{nM}$ free calcium. Presumably, under these conditions the free calcium concentration is not altered in response to muscarine or LHRH. They suggest that calcium plays a permissive role for $I_{M}$ suppression and overrecovery.

\section{References}

Adams PR, Brown DA (1982) Synaptic inhibition of the M-current: slow excitatory post-synaptic potential mechanism in bullfrog sympathetic neurones. J Physiol (Lond) 332:263-272.

Adams PR, Brown DA, Constanti A (1982a) M-currents and other potassium currents in bullfrog sympathetic neurones. J Physiol (Lond) 330:537-572.

Adams PR, Brown DA, Constanti A (1982b) Pharmacological inhibition of the M-current. J Physiol (Lond) 332:223-262.

Adams PR, Jones SW, Pennefather P, Brown DA, Koch C, Iancaster B (1986) Slow synaptic transmission in frog sympathetic ganglia. J Exp Biol 124:256-285.

Akasu T, Ito M, Nakano T, Schneider CR, Simmons MA, Tanaka T, Tokimasa T, Yoshida M (1993) Myosin light chain kinase occurs in bullfrog sympathetic neurons and may modulate voltage-dependent potassium currents. Neuron 11:1133-1145.

Béhé P, Sandmeier K, Meves H (1992) The effect of arachidonic acid on the M current of NG108-5 neuroblastoma $\times$ glioma hybrid cells. Pfluegers Arch 422:120-128.

Blackwell GJ, Flower RJ (1983) Inhibition of phospholipase. Br Med Bull 39:260-264.

Bley KR, Tsien RW (1990) Inhibition of $\mathrm{Ca}^{2+}$ and $\mathrm{K}^{+}$channels in sympathetic neurons by neuropeptides and other ganglionic transmitters. Neuron 2:379-391.

Boland LM, Bean BP (1993) Modulation of N-type calcium channels in bullfrog sympathetic neurons by luteinizing hormone-releasing hormone. Kinetics and voltage dependence. J Neurosci 13:516-533.

Bosma MM, Bernheim L, Leibowitz MD, Pfaffinger PJ, Hille B (1991) Modulation of $M$ current in frog sympathetic ganglion cells. In: $G$ proteins and signal transduction (Nathanson NM, Harden TK, eds), pp 43-59. New York: Rockefeller UP. 
Brown DA (1988) M-currents: an update. Trends Neurosci 11:294 299.

Brown DA, Adams PR (1980) Muscarinic suppression of a novel voltage-sensitive $\mathrm{K}^{+}$current in a vertebrate neurone. Nature 283: 673-676.

Brown DA, Marrion NV, Smart TG (1989) On the transduction mechanism for muscarine-induced inhibition of $\mathrm{M}$-current in cultured rat sympathetic neurones. J Physiol (Lond) 413:469-488.

Carlson RO, Levitan IB (1990) Constant turnover of arachidonic acid and inhibition of a potassium current in Aplysia giant neurons. $\mathrm{J}$ Membr Biol 116:261-272.

Chan PH, Fishman RA (1985) Free fatty acids, oxygen free radicals, and membrane alterations in brain ischemia and injury. In: Cerebrovascular diseases (Plum F, Pulsinelli W, eds), pp 161-171. New York: Raven.

Chen H, Kurenny DE, Smith PA (1993) Heparin prevents M-current over-recovery but not M-current supression in bullfrog ganglion neurones. Brain Res 625:323-327.

Conklin BR, Brann RM, Bucklcy TI, Axelrod J (1988) Stimulation of arachidonic acid release and inhibition of mitogenesis by cloned genes for muscarinic receptor subtypes expressed in A9 L cells. Proc Natl Acad Sci USA 85:8698-8702.

Egan RW, Gale PH (1985) Comparative biochemistry of lipoxygenase inhibitors. In: Prostaglandins, leukotrienes, and lipoxins (Bailey JM, ed), pp 593-607. New York: Plenum.

Forscher P, Oxford GS, Schulz D (1986) Noradrenaline modulates calcium channels in avian dorsal root ganglion cells through tight receptor-channel coupling. J Physiol (Lond) 379:131-144.

Fukuda K, Higashida H, Kubo T, Maeda A, Akiba I, Bujo H, Mishina $\mathrm{M}$, Numa S (1988) Selective coupling with $\mathrm{K}^{+}$currents of muscarinic acetylcholine receptor subtypes in NG108-15 cells. Nature 335: 355-358.

Hamill O, Marty A, Neher E, Sakmann B, Sigworth FJ (1981) Improved patch-clamp techniques for high-resolution current recording from cells and cell-free membrane patches. Pfluegers Arch 391:85100 .

Hartzell HC, Méry P-F, Fischmeister R, Szabo G (1991) Sympathetic regulation of cardiac calcium current is due exclusively to cAMPdependent phosphorylation. Nature 351:573-576.

Hille B (1992) Ion channels of excitable cells. Sunderland, MA: Sinauer.

Jacquin T, Champagnat J, Madamba S, Denavit-Subié M, Siggins RG (1988) Somatostatin depresses excitability in neurons of the solitary tract complex through hyperpolarization and augmentation of $I_{\mathrm{M}}$, a non-inactivating voltage-dependent outward current blocked by muscarinic agonists. Proc Natl Acad Sci USA 85:948-952.

Jones SW (1992) Time course of receptor-channcl coupling in frog sympathetic neurons. Biophys J 60:502-507.

Kaczmarek LK, Levitan IB (1987) Neuromodulation. The biochemical control of neuronal excitability. New York: Oxford UP.

Kasai $\mathrm{H}$ (1991) Tonic inhibition and rebound facilitation of a neuronal calcium channel by a GTP-binding protein. Proc Natl Acad Sci USA 88:8855-8859.

Kono Y, Takahashi MA, Asada K (1976) Oxidation of manganous pyrophosphate by superoxide radicals and illuminated spinach chloroplasts. Arch Biochem Biophys 174:454-462.

Korn SJ, Horn R (1990) Nordihydroguaiaretic acid inhibits voltageactivated $\mathrm{Ca}^{2+}$ currents independently of lipoxygenase inhibition. Mol Pharmacol 38:524-530.

Krishtal OA, Pidoplichko VI (1980) A receptor for protons in the nerve cell membrane. Neuroscience 5:2325-2327.

Kuffler SW, Sejnowski TJ (1983) Peptidergic and muscarinic excitation at amphibian sympathetic synapses. J Physiol (Lond) 341:257278 .

Lopez HS (1992) Kinetics of $G$ protein-mediated modulation of the potassium M-current in bullfrog sympathetic neurons. Neuron 8:725736.

Lopez HS, Adams PR (1989) A G protein mediates the inhibition of the voltage-dependent potassium $M$ current by muscarine, LHRH, substance P and UTP in bullfrog sympathetic neurons. Eur J Neurosci 1:529-542.

Marrion NV (1993) Selective reduction of one mode of M-channel gating by muscarine in sympathetic neurons. Neuron 11:77-84.
Marrion NV, Zucker RS, Marsh SJ, Adams PR (1991) Modulation of M-current by intracellular $\mathrm{Ca}^{2+}$. Neuron 6:533-545.

Marrion NV, Adams PR, Gruner W (1992) Multiple kinetic states underlying macroscopic M-currents in bullfrog sympathetic neurons. Proc R Soc Lond [Biol] 248:207-214.

Moore SD, Madamba SG, Joëls M, Siggins GR (1988) Somatostatin augments the M-current in hippocampal neurons. Science 239:278280.

Needleman P, Turk J, Jakschik BA, Morrison AR, Lefkowith JB (1986) Arachidonic acid metabolism. Annu Rev Biochem 55:69-102.

Nicoll RA (1988) The coupling of neurotransmitter receptors to ion channels in the brain. Science 241:545-551.

O'Donnell KA, Howlett AC (1991) Muscarine receptor binding is inhibited by quinacrine. Neurosci Lett 127:46-48.

Onsager L (1931) Reciprocal relations in irreversible processes. Phys Rev 37:405-426.

Pfaffinger PJ (1988) Muscarine and t-LHRH suppress M-current by activating an IAP-insensitive G protein. J Neurosci 8:3343-3353.

Pfaffinger PJ, Leibowitz MD, Subcrs EM, Nathanson NM, Almcrs W, Hille B (1988) Agonists that suppress M-current elicit phosphoinositide turnover and $\mathrm{Ca}^{2+}$ transients, but these events do not explain M-current suppression. Neuron 1:477-484.

Rodiguin NM, Rodiguina EN (1964) Consecutive chemical reactions. Mathematical analysis and development. New Jersey: Van Nostrand.

Samples DR, Sprague EA, Harper MJK, Herlihy JT (1989) In vitro adsorption losses of arachidonic acid and calcium ionophore A23187. Am J Physiol 257:C1166-C1170.

Scherer RW, Breitwieser GE (1990) Arachidonic acid metabolites alter $\mathrm{G}$ protein-mediated signal transduction in heart. J Gen Physiol 96: 735-755.

Schweitzer P, Madamba S, Siggins GR (1990) Arachidonic acid metabolites as mediators of somatostatin-induced increase of neuronal M-current. Nature 346:464-467.

Schweitzer P, Madamba S, Champagnat J, Siggins GR (1993) Somatostatin inhibition of hippocampal CAl pyramidal neurons: mediation by arachidonic acid and its metabolites. J Neurosci 13:20332049.

Simmons MA, Mather RJ (1991) Selectivity of the effects of guanosisne-5'-O-(2-thiodiphosphate) on agonist inhibition of the M-current in amphibian sympathetic neurons. $J$ Neurosci 11:2130-2134.

Simmons MA, Mather RJ, Schneider CR (1992) Intracellular guanosine- $5^{\prime}-O$-(2-thiodiphosphate) alters the dynamics of receptor-mediated responses in bullfrog sympathetic neurons. Mol Pharmacol 41: 527-534.

Sims SM, Singer JJ, Walsh JV (1988) Antagonistic adrenergic-muscarinic regulation of $M$ current in smooth muscle cells. Science 239 190-192.

Szabó ZG (1969) Kinetic characterization of complex reaction systems. In: Comprehensive chemical kinetics (Bamford $\mathrm{CH}$, Tipper CFH, eds), pp 1-79. Amsterdam: Elsevier.

Tokimasa T, Akasu T (1990) ATP regulates muscarine-sensitive potassium current in dissociated bull-frog primary afferent neurones. J Physiol (Lond) 426:241-264

Vacher P, McKenzie J, Dufy B (1989) Arachidonic acid affects membrane ionic conductances of $\mathrm{GH}_{3}$ pituitary cells. Am J Physiol 257: E203-E211.

Villarroel A (1993) Suppression of neuronal potassium A-current by arachidonic acid. FEBS Lett 335:184-188.

Volwek JJ, Pieterson WA, Haas GH (1974) Histidine at the active site of phospholipase $A_{2}$. Biochemistry 13:1446-1454.

Yakel JL (1991) The neuropeptide FMRFa both inhibits and enhances the $\mathrm{Ca}^{2+}$ current in dissociated Helix neurons via independent mechanism. J Neurophysiol 65:1517-1527.

Yatani A, Brown AM (1989) Rapid $\beta$-adrenergic modulation of cardiac calcium channel currents by a fast $G$ protein pathway. Science 245:71-74.

Yu SP, Adams PR, Rosen AD (1991) Effect of arachidonic acid pathway inhibitors on calcium regulated $M$ current enhancement. Soc Neurosci Abstr 17:67.

Yu SP, O'Malley DM, Adams PR (1994) Regulation of M current by intracellular calcium in bullfrog sympathetic ganglion neurons. J Neurosci 14:3487-3499. 